\title{
FLOWSHEET FOR ALUMINUM REMOVAL FROM SLUDGE BATCH 6
}

\author{
J. A. Pike \\ J. M. Gillam
}

December 2008

Savannah River National Laboratory

Savannah River Nuclear Solutions

Savannah River Site

Aiken, SC 29808

Prepared for the U.S. Department of Energy Under

Contract Number DE-AC09-08SR22470

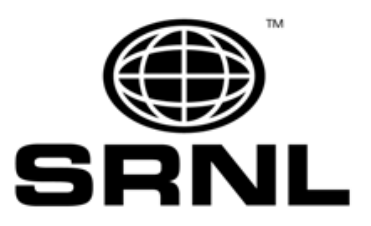




\section{DISCLAIMER}

This work was prepared under an agreement with and funded by the U.S. Government. Neither the U. S. Government or its employees, nor any of its contractors, subcontractors or their employees, makes any express or implied:

1. warranty or assumes any legal liability for the accuracy, completeness, or for the use or results of such use of any information, product, or process disclosed; or

2. representation that such use or results of such use would not infringe privately owned rights;

or

3. endorsement or recommendation of any specifically identified commercial product, process, or service.

Any views and opinions of authors expressed in this work do not necessarily state or reflect those of the United States Government, or its contractors, or subcontractors.

Printed in the United States of America

Prepared For

U.S. Department of Energy 
KEYWORDS: HLW Sludge, Aluminum Dissolution

\title{
FLOWSHEET FOR ALUMINUM REMOVAL FROM SLUDGE BATCH 6
}

\author{
J. A. Pike \\ J. M. Gillam
}

December 2008

Savannah River National Laboratory

Savannah River Nuclear Solutions

Savannah River Site

Aiken, SC 29808

Prepared for the U.S. Department of Energy Under

Contract Number DE-AC09-08SR22470

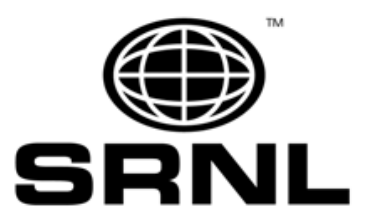




\section{REVIEWS AND APPROVALS}

\section{AUTHORS:}

J. A. Pike, Engineering Modeling and Simulation

Date

J. M. Gillam, LW Sludge and Salt Planning

Date

\section{TECHNICAL REVIEWERS:}

M. P. Jones, Engineering Modeling and Simulation

Date

K. B. Martin, Tank Farm Process Engineering

Date

T. B. Caldwell, Technology Development Engineering

Date

\section{APPROVERS:}

H. B. Shah, Lead, LW Sludge and Salt Planning

Date

A. W. Wiggins, Manager, Tank Farm Process Engineering

Date

M. T. Keefer, Project Owner, Technology Development and Tank Closure

Date

S. J. Hensel, Manager, Engineering Modeling and Simulation

Date 


\section{SUMMARY}

Samples of Tank 12 sludge slurry show a substantially larger fraction of aluminum than originally identified in sludge batch planning. The Liquid Waste Organization (LWO) plans to formulate Sludge Batch 6 (SB6) with about one half of the sludge slurry in Tank 12 and one half of the sludge slurry in Tank 4. LWO identified aluminum dissolution as a method to mitigate the effect of having about 50\% more solids in High Level Waste (HLW) sludge than previously planned. Previous aluminum dissolution performed in a HLW tank in 1982 was performed at approximately $85^{\circ} \mathrm{C}$ for 5 days and dissolved nearly $80 \%$ of the aluminum in the sludge slurry. In 2008 , LWO successfully dissolved $64 \%$ of the aluminum at approximately $60^{\circ} \mathrm{C}$ in 46 days with minimal tank modifications and using only slurry pumps as a heat source. This report establishes the technical basis and flowsheet for performing an aluminum removal process in Tank 51 for SB6 that incorporates the lessons learned from previous aluminum dissolution evolutions.

For SB6, aluminum dissolution process temperature will be held at a minimum of $65^{\circ} \mathrm{C}$ for at least 24 days, but as long as practical or until as much as $80 \%$ of the aluminum is dissolved.

As planned, an aluminum removal process can reduce the aluminum in SB6 from about 84,500 $\mathrm{kg}$ to as little as $17,900 \mathrm{~kg}$ with a corresponding reduction of total insoluble solids in the batch from $246,000 \mathrm{~kg}$ to $131,000 \mathrm{~kg}$. The extent of the reduction may be limited by the time available to maintain Tank 51 at dissolution temperature. The range of dissolution in four weeks based on the known variability in dissolution kinetics can range from 44 to more than $80 \%$. At $44 \%$ of the aluminum dissolved, the mass reduction is approximately $1 / 2$ of the mass noted above, i.e., $33,300 \mathrm{~kg}$ of aluminum instead of $66,600 \mathrm{~kg}$. Planning to reach $80 \%$ of the aluminum dissolved should allow a maximum of 81 days for dissolution and reduce the allowance if test data shows faster kinetics. $47,800 \mathrm{~kg}$ of the dissolved aluminum will be stored in Tank 8 and 21,000 kg will be stored in saltcake via evaporation. Up to $77 \%$ of the total aluminum planned for SB6 may be removed via aluminum dissolution.

Storage of the aluminum-laden supernate in Tank 8 will require routine evaluation of the free hydroxide concentration in order to maintain aluminum in solution. Periodic evaluation will be established on concurrent frequency with corrosion program samples as previously established for aluminum-laden supernate from SB5 that is stored in Tank 11. 


\section{CONTENTS}

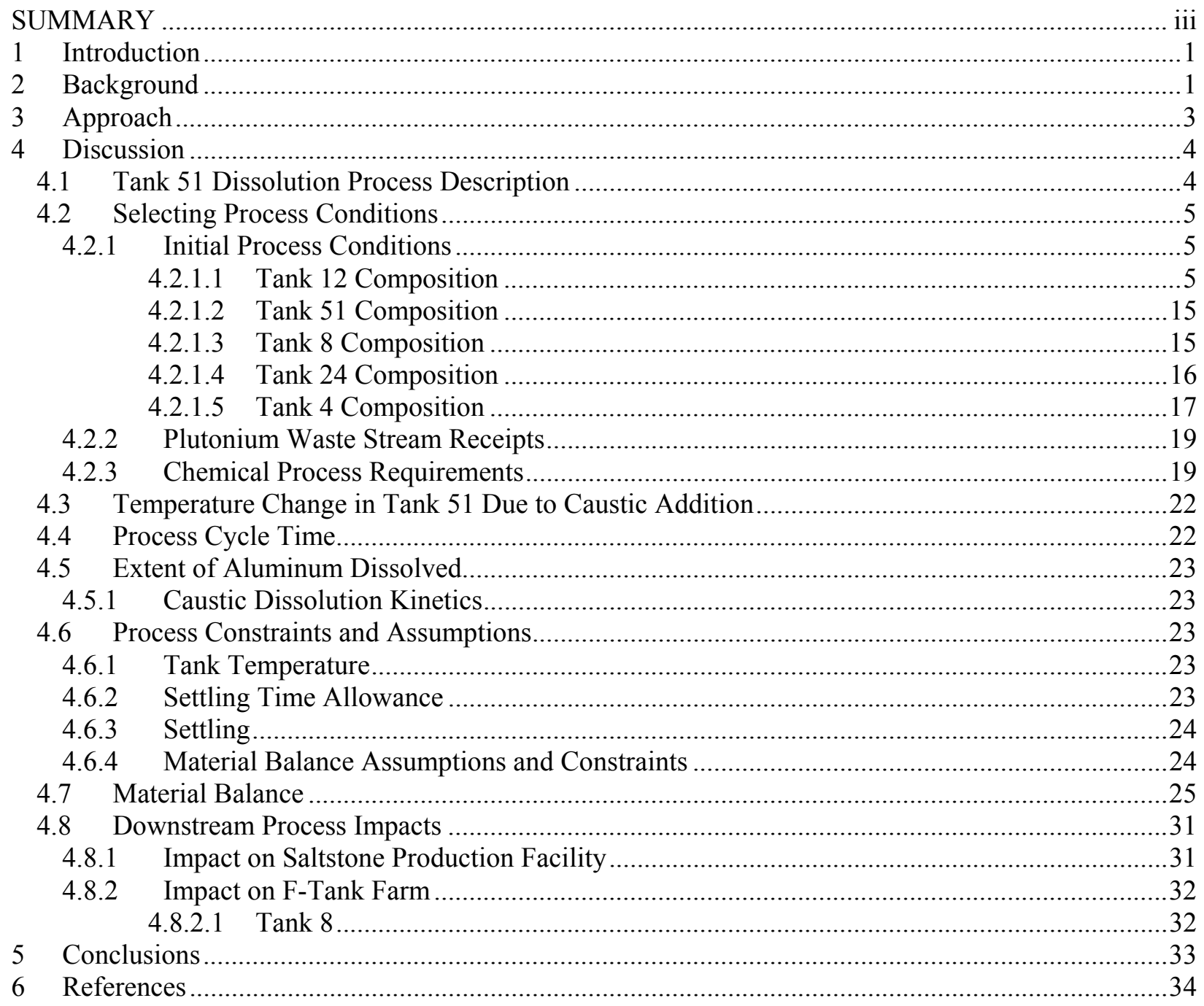

\section{LIST OF FIGURES}

Figure 1: Aluminum Removal Flow Diagram for Sludge Batch 6..................................................

Figure 2: Tank 12 Volume and Temperature Data from Monthly Reports ..............................................

Figure 3: Tank 12 Radiolytic Decay Heat Estimation......................................................................... 10

Figure 4: Dissolution Conditions for Sludge Batch 6 (based on gibbsite solubility) .............................20

Figure 5: Sludge Washing Conditions for Sludge Batch 6 (based on gibbsite solubility) .......................21

Figure 6: Aluminum Balance for Aluminum Dissolution in Tank 51 ..................................................31

\section{LIST OF TABLES}

Table 1: Historical Summary of Tank 12 Since Last Waste Receipt ....................................................6 
Table 2: Tank 12 Supernate Sample Data Since Last Waste Receipt ....................................................

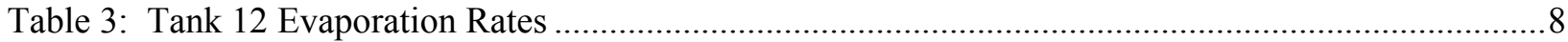

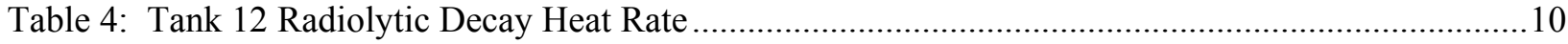

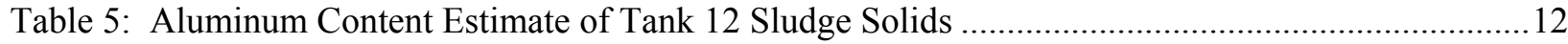

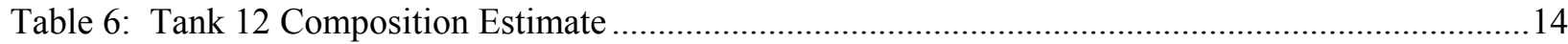

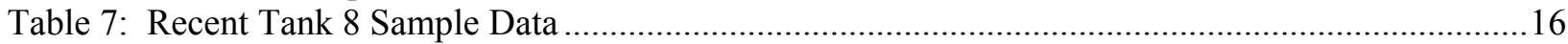

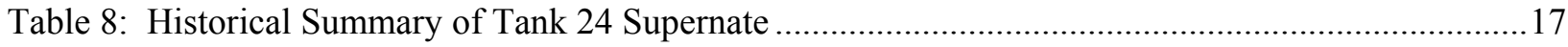

Table 9: Tank 24 Supernate Composition Estimate ............................................................................ 17

Table 10: Initial Composition Estimates for Aluminum Dissolution of Sludge Batch 6 ........................19

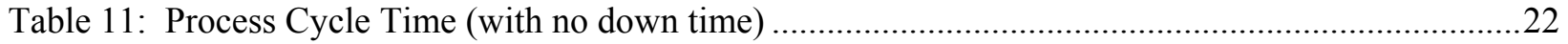

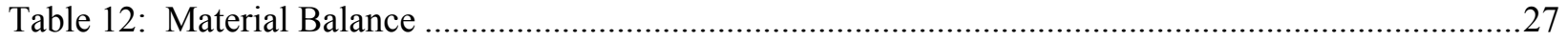

Table 13: Ionic Concentration Data in Molarity for Al-Laden Supernate Stored in Tank 8 Compared

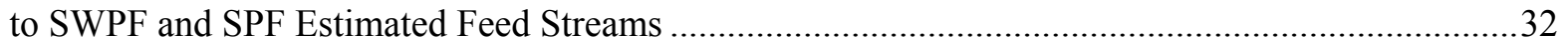

\section{LIST OF ACRONYMS}

LWO Liquid Waste Organization

LTAD Low Temperature Aluminum Dissolution

DWPF Defense Waste Processing Facility

SPF Saltstone Processing Facility

SWPF Salt Waste Processing Facility

SB5 Sludge Batch 5

SB6 Sludge Batch 6

ARP Actinide Removal Process

MCU Modular Caustic-side Solvent Extraction Unit

WCS Waste Characterization System

HLW High Level Waste 


\section{INTRODUCTION}

Samples of Tank 12 sludge slurry show a substantially larger fraction of aluminum than originally identified in sludge batch planning. The Liquid Waste Organization (LWO) plans to formulate Sludge Batch 6 (SB6) with about one half of the sludge slurry in Tank 12 and one half of the sludge slurry in Tank 4. Tank 12 sludge contains a high aluminum content that was selected as candidate sludges for aluminum dissolution. ${ }^{1}$ The current plan includes dissolving and removing a significant portion of the aluminum before mixing the Tank 12 sludge slurry with other waste that constitutes the sludge batch. This report establishes the technical basis and flowsheet for performing an aluminum removal process in Tank 51 for SB6 that incorporates the lessons learned from previous aluminum dissolution evolutions.

\section{BACKGROUND}

An evaluation of sludge mass remaining in the High Level Waste (HLW) Tank Farms shows about 50\% more solids in the sludge than previously estimated. ${ }^{2}$ The new estimate will affect the estimated life cycle cost and schedule for HLW disposition. Consequently, Washington Savannah River Company chartered a LWO Technology Development team to evaluate techniques to mitigate these life cycle impacts. The Technology Development Team focused on three areas: reducing the sludge mass, new melter technology, and DWPF flowsheet improvements.

One promising mitigation option was aluminum dissolution, which offers the potential for significantly reducing the quantity of sludge solids sent to the DWPF, thus, reducing the number of canisters produced. Aluminum adversely affects sludge slurry rheology and glass viscosity, and adds to overall waste volume. Aluminum is dissolved from sludge waste into the supernate by treatment with caustic at moderate to high temperatures, where it is subsequently removed by decantation and water washing.

As part of Sludge Batch 5 (SB5) preparation, the LWO successfully completed a low cost version of an aluminum dissolution process in Tank 51 with minimal tank modification. The process, dubbed Low Temperature Aluminum Dissolution (LTAD), was a variation of the baseline aluminum dissolution process operating at a temperature of $55-65^{\circ} \mathrm{C}$ rather than up to $90^{\circ} \mathrm{C}$. This variation used the existing slurry pumps as the primary source of heat to warm the tank and maintain temperature. This process temperature was well within all existing safety limits for operating the waste tank, thus, required no special modification. The effect of lower temperature substantially increases the time required to dissolve the aluminum. In a 46 day dissolution cycle at process temperature, about $64 \%$ of the aluminum dissolved verses nearly $80 \%$ at $85^{\circ} \mathrm{C}$ in less than 5 days in $1982 .{ }^{3}$ The reduction in aluminum mass in SB5 from LTAD directly reduced the total estimated canister production by 92 canisters at $34 \%$ waste loading. ${ }^{4}$

Aluminum solids in the sludge are believed to be present primarily in three forms - aluminum trihydrate or gibbsite, alumina monohydrate or boehmite, and aluminosilicate. With caustic treatment, the gibbsite form dissolves readily at the relatively low dissolving temperatures possible in the waste tanks. The boehmite form dissolves much more slowly and is somewhat less soluble than gibbsite. In addition to chemical form, the physical forms of the boehmite and gibbsite particles in the sludge slurry have an effect on the rate of dissolution, especially the specific surface area of aluminum exposed to the dissolving solution. The aluminosilicate has such low solubility in waste slurries that it is generally considered insoluble. 
Equation (1) shows a kinetic model developed for dissolving aluminum from SRS sludge that is based on dissolution test data, in tank demonstration data, and literature data. ${ }^{5}$ The rate model is based on dissolving boehmite, which is believed to be the slowest dissolving form of aluminum in the waste.

(1) $\quad t=\frac{\alpha F(w f, \alpha)}{\left(\eta^{0} \gamma_{ \pm}^{1 / 2} A\right) \sqrt{C_{O H}^{0}}} e^{\frac{14800}{T}}$

where

$$
\begin{aligned}
\mathrm{t}= & \text { Dissolution time, } \mathrm{hr} \\
\mathrm{F}(\mathrm{wf}, \alpha)= & \frac{1}{\sqrt{\alpha(\alpha-1)}} \mathrm{Ln}\left|\frac{(\sqrt{\alpha}-\sqrt{\alpha-1})(\sqrt{\alpha-1+\mathrm{wf}}+\sqrt{\alpha-1})}{(\sqrt{\alpha}+\sqrt{\alpha-1})(\sqrt{\alpha-1+\mathrm{wf}}-\sqrt{\alpha-1})}\right| \\
\alpha= & \text { Mole ratio at initial conditions of free } \mathrm{OH} \text { ion in the liquid phase relative to } \mathrm{Al} \text { in the solid phase, dimensionless } \\
\mathrm{C}_{\mathrm{OH}}^{0}= & \text { Initial liquid phase concentration of free } \mathrm{OH} \text { ion in molal units, gmol/kg water } \\
\mathrm{T}= & \text { Dissolution operating temperature, } \mathrm{K} \\
\mathrm{wf}= & \text { Weight fraction of initial Al remaining in solids at the conclusion of the dissolution process, dimensionless } \\
\eta^{0}= & \text { the initial specific surface area of aluminum hydroxide solids, } \mathrm{m}^{2} / \mathrm{gmol} \mathrm{Al} \\
\gamma_{ \pm}= & \text {Constant defined in the batch dissolution model development equivalent to variation of }{ }_{25} \mathrm{a}_{\mathrm{NaOH}}, \text { activity of } \\
& \quad \text { NaOH in water at } 25^{\circ} \mathrm{C}, \text { with free OH molality for the liquid phase where }{ }_{25} \mathrm{a}_{\mathrm{NaOH}} \sim \gamma_{ \pm} \mathrm{C}_{\mathrm{OH}}, \\
& \text { dimensionless. } \\
\mathrm{A}= & \text { Boehmite dissolution reaction pre-exponential rate constant, mol Al- } \mathrm{m}^{-2}-\mathrm{hr}^{-1}-\left(\mathrm{mol} \mathrm{OH} / \mathrm{kg} \mathrm{water}^{1 / 2}\right.
\end{aligned}
$$

The rate equation is based on a number of simplifying assumptions, including:

- Sufficient solids and liquid mixing is provided,

- Aluminum hydroxide solids are primarily present in the form of boehmite,

- The dissolution endpoint composition is selected such that the solubility limit does not influence the dissolution rate at the dissolution operating temperature,

- The change in liquid phase water mass is negligible over the dissolution time period,

- The operating temperature is constant over the dissolution time period, and

- The liquid phase sodium hydroxide activity is approximately proportional to the molal concentration of free hydroxide ion in solution.

The rate equation is applicable for hydroxide ion concentrations less than $6.8 \mathrm{M}$. A shift in reaction order occurs above this concentration and the rate equation would be expected to over-estimate times to dissolve aluminum while the liquid phase is at free hydroxide ion concentration greater than $6.8 \mathrm{M}$.

The group of constants, $\left(\eta^{0} \gamma_{ \pm}^{1 / 2} \mathrm{~A}\right)$, was fitted to simulated and real waste dissolution data. To best represent SRS waste, the recommended constant to apply was 2E15. One might note that the group of constants contains the initial specific surface area of aluminum hydroxide. Little or no data is available to determine the specific surface area. However, the value is a constant for any given dissolution and may vary some from batch to batch. Therefore, application of this fitted parameter includes the assumption that the specific surface area is about the same from batch to batch. Considering that the targeted sludge for aluminum dissolution all originated from the same process in H-Area, the aluminum particles in the sludge are likely to be similar from batch to batch. 
Testing with Tank 12 sludge at $60^{\circ} \mathrm{C}$ shows most of the aluminum dissolved in 10 days. ${ }^{6}$ This test implied that dissolution could be relatively quick, but the fraction of gibbsite in Tank 12 sludge was not determined. Gibbsite dissolution rate is faster than boehmite under identical conditions. Furthermore, dissolution rates in laboratory testing appear to be substantially faster than observed in a waste tank. In preparation for aluminum dissolution for SB5, a laboratory simulation of the dissolution process was performed on a sample of sludge slurry from SB5 at $55^{\circ} \mathrm{C}$. The laboratory testing simulating SB5 dissolution showed that the dissolution rate observed in the laboratory tests was much faster than predicted by this equation. When compared to the observations of dissolution in Tank 51, the laboratory dissolution test reached the same extent of dissolution in the first 10 days as was observed in the first 20 days in Tank $51 .^{3}$ The dissolution rate observed in Tank 51 was still faster than predicted by the model.

Inherent in this equation is the assumption that the reaction rate is limited by the chemical reaction rate at the surface of the particle. Dissolution of aluminum from SB5 was about 3.5 times faster than predicted, most likely because the specific surface area was larger than suggested by the fitted value for $\left(\eta^{0} \gamma_{ \pm}^{1 / 2} A\right)$. Since there was inadequate data to change the value for the rate constant, the conclusion from the dissolution experience on SB5 recommended continued use of the same rate constant until additional data is available to adequately account for particle characteristics.

\section{APPROACH}

The flowsheet and parameters were modeled after the flowsheet for LTAD. The aluminum-laden supernate is destined for Tank 8 in this case.

The initial conditions in Tank 51 for aluminum dissolution for SB6 assume a small heel from SB5 preparation. The SB5 heel composition is estimated from composition projections after preparation is complete.

The estimation or projection of the composition of the sludge slurry from Tank 12 is much more complicated than estimating the composition for SB5 since the actual sludge slurry to be processed has not yet been transferred to Tank 51. Samples from Tank 12 are planned, but limited data is available to use for this estimate. The liquid phase is estimated based on the historical record of Tank 12 and estimated changes to the composition due to the effects of evaporation, carbon dioxide absorption from the atmosphere, and radiolysis of sodium nitrate. In addition, the compositions of the solutions added to Tank 12 used to slurry the waste are included in the material balance to estimate the Tank 12 sludge slurry composition. The solids phase other than aluminum is practically inert relative to aluminum dissolution, so the aluminum content of the solids is based on sample data.

The composition of Tank 8 is estimated by samples of waste similar to what is expected to remain in the heel.

Tank 24 composition is based on the best available sample data.

Tank 4 sludge slurry composition is based on existing projections of the composition at the end of waste removal.

The process parameters are then determined based on the estimated composition of the sludge slurry. OLI Stream Analyzer ${ }^{\mathrm{tm}}$ is used to estimate the solubility of aluminum in order to refine the preliminary process parameters for Tank 12 sludge slurry. ${ }^{7}$ Using the dissolution rate model for estimating duration, the target process temperature is determined by balancing the target extent of dissolution with time available to 
perform dissolution. The range of aluminum predicted to dissolve is then determined by the known variation in parameters.

A material balance is produced using the identified conditions and at the maximum extent of aluminum dissolution anticipated. The maximum extent of dissolution is used to demonstrate the conditions necessary to store the aluminum-laden decant in Tank 8 without precipitating aluminum. In addition, the process conditions generated will maximize the extent of aluminum dissolved for any dissolution time less than necessary to reach the maximum. The material balance will be used to estimate the composition of the interface streams to feed existing processes.

\section{DISCUSSION}

\subsection{Tank 51 Dissolution Process Description}

For the purposes of this flowsheet the dissolution process consists of the following steps. Procedure requirements will be further detailed in an Operations Plan.

1. Valve out cooling water to Tank 51.

2. Unload $50 \%$ sodium hydroxide solution to Tank 51 via HPT 7 and HPT 8.

3. Use slurry pumps to mix Tank 51 periodically during the batch transfers of caustic from HPT 7 and HPT 8 to Tank 51.

4. Use slurry pumps to increase slurry temperature in Tank 51 and maintain the temperature as necessary. A supplemental heater may be used if installed. If necessary, cooling coils may be used to avoid exceeding the upper operating temperature limits.

5. Periodically mix tank for number of days available. Supernate analysis results will indicate the rate and extent of dissolution, and be used to finalize the dissolution time to be allotted.

6. Turn off slurry pumps.

7. Settle for as long as allowable by the Q-Time program for a maximum decant to Tank 8 .

8. Decant the maximum amount of aluminum-laden supernate to decant storage tank, Tank 8.

9. Start SB6 washing prior to the planned receipt of sludge from F-Area Tank Farm (Tank 4).

10. Proceed with SB6 preparation by transferring sludge slurry from F-Area Tank Farm (Tank 4) and $\mathrm{Pu}$ waste receipts from $\mathrm{H}$ Canyon, as planned.

11. Continue washing SB6 for preparation as feed to DWPF.

12. Store aluminum-laden supernate for feed to the Salt Waste Processing Facility (SWPF) or any other salt waste process installed in the future.

Figure 1 shows the process flow diagram in context with downstream processes.

The HLW Tank Farms has limited volume for storing the aluminum-laden supernate generated from the aluminum dissolution process. Tank 8 is used to store the aluminum-laden supernate from this process, because Tank 8 has space available that cannot be used for bulk sludge storage. The supernatant is stored without mixing with other supernates to avoid inadvertent reprecipitation of the aluminum. However, if supernate is transferred into or left in Tank 8 before transfer from Tank 51, the blended liquid needs to be evaluated for the risk of precipitating aluminum and chemical adjustments made to the blending supernate, if necessary, before mixing the liquids. The aluminum-laden supernate may be purposely blended at any time for salt waste processing and final disposition at the SPF. 


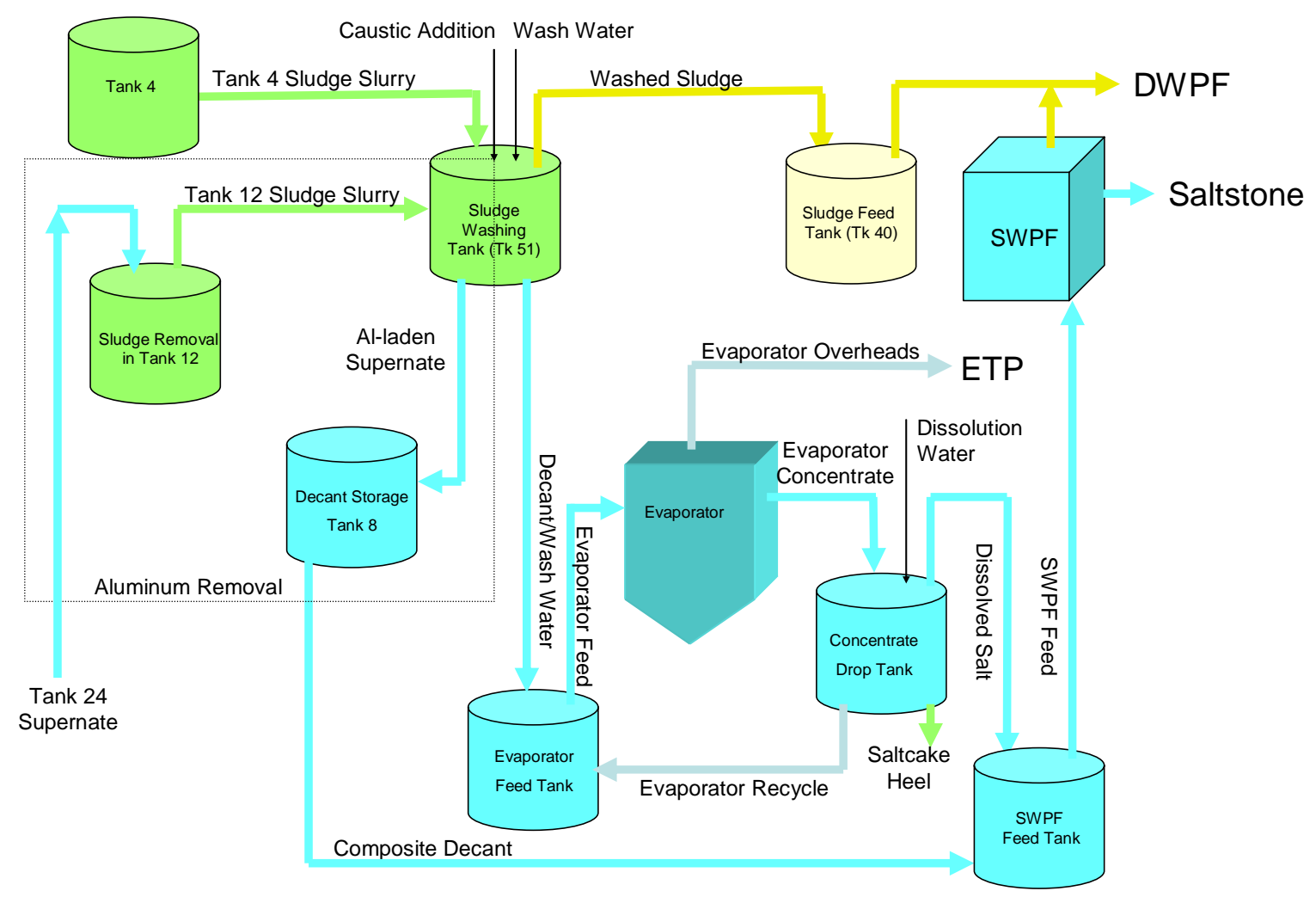

Figure 1: Aluminum Removal Flow Diagram for Sludge Batch 6

\subsection{Selecting Process Conditions}

\subsubsection{Initial Process Conditions}

Primarily, SB6 will consist of about half of the sludge slurry in Tank 12 and half of the sludge slurry in Tank 4. Only the high aluminum content slurry from Tank 12 will be included in this aluminum dissolution process. Other sludge slurry or additions may be added to the sludge batch, but after aluminum dissolution, thus, not affecting the composition for the dissolution process. The heel from SB5 in Tank 51 is anticipated to be about 7". The start of aluminum dissolution will consist of the sludge slurry from Tank 12 combined with the heel remaining in Tank 51 from SB5 preparation.

\subsubsection{Tank 12 Composition}

The composition of the sludge in Tank 12 consists of two parts, a solid phase and a liquid phase. The composition of the solid phase is discussed in Section 4.2.1.1.5. The liquid phase composition is estimated by analyzing the transfer and sample history of the tank.

Tank 12 last received a transfer of waste in June 1973. ${ }^{8}$ Supernate was transferred from the tank in April 1976 and again in September 1978. The remaining liquid was allowed to concentrate by natural evaporation of water via the tank ventilation. Around March 1983, the liquid level and solids level was 
approximately the same. However, significant rain water in-leakage restored a liquid layer in May 1984. The water evaporated and the liquid level generally fell below the top of the solids level again by February 1985. Water likely continued to evaporate until the water vapor pressure of the supernate was reduced to match the average water vapor pressure in the atmosphere. The evaporation rate slowed down as the liquid phase composition approached this point. Further complicating the chemistry in the liquid phase is the fact that carbon dioxide from the atmosphere is absorbed in the supernate, depleting the free hydroxide until the $\mathrm{pH}$ is in equilibrium with the saturation concentration of carbonates. Furthermore, nitrates in the liquid are converted to nitrites by radiolysis. Liquid was added to the tank between November 2004 and January 2005 in preparation of waste removal. Additional liquid was added to the tank by two supernate transfers from Tank 51 in April and May 2008.

The liquid phase composition is determined first by estimating the likely composition of the supernate after the last waste transfer into the tank in 1973. Then, the liquid composition after the last transfer in 1978 is adjusted for evaporation and carbon dioxide absorption. Some salts in solution will precipitate as water evaporates. The liquid phase is then adjusted for the liquid additions in 2004, followed by another concentration step for a short period of evaporation, and finally by adjusting for the supernate transfers. In order to determine if all of the salt precipitated will redissolve with the liquid additions, salt precipitation and dissolution is evaluated by using OLI Stream Analyzer ${ }^{\mathrm{tm}}$ to simulate evaporation.

Table 1 and Table 2 summarize Tank 12 transfer and sample history since the last transfer into Tank 12 . Ideally, the sample data could be used to establish a trend for composition changes expected, but the limited supernate sample data varies considerably without establishing a distinct trend. The sample variability is consistent with what would be expected from single determinations from dip samples. ${ }^{9}$ In addition, the 1984 sample is likely dilute due to the rain water intrusion. If a trend could be established, the data could then be used to estimate the composition after the last transfer out Tank 12 and composition changes calculated to account for changes since the transfer. Without an established trend, the average of the four samples taken between 1975 and 1981 is used to estimate the actual composition after the last transfer out of the tank in 1978.

Table 1: Historical Summary of Tank 12 Since Last Waste Receipt

\begin{tabular}{|c|c|}
\hline June 1973 & Last received waste ${ }^{10}$ \\
\hline April 1975 & Supernate sampled ${ }^{11}$ \\
\hline April 1976 & Transferred 242,000 gallons of supernate from Tank $12^{10}$ \\
\hline September 1978 & Transferred 107,000 gallons of supernate from Tank 12 to Tank $13^{10}$ \\
\hline December 1978 & Supernate sampled ${ }^{11}$ \\
\hline April 1980 & Supernate sampled $^{11}$ \\
\hline September 1981 & Supernate sampled ${ }^{11}$ \\
\hline March 1983 & Supernate fell below sludge solids surface ${ }^{10}$ \\
\hline May 1984 & $\begin{array}{l}\text { Rain water in-leakage }{ }^{12} \\
(17,000 \text { gallons based on monthly increase in liquid level })^{10}\end{array}$ \\
\hline November 1984 & Supernate sampled ${ }^{11}$ \\
\hline February 1985 & Supernate sample attempted, but vial was empty ${ }^{11}$ \\
\hline February 1985 & $\begin{array}{l}\text { Supernate fell below sludge solids surface (based on lack of liquid for } \\
\text { sampling) }\end{array}$ \\
\hline $\begin{array}{l}\text { November } 2004- \\
\text { January } 2005\end{array}$ & Initial "rewetting" solution added ${ }^{13}$ \\
\hline April 2008 & Transfer from Tank 51 to Tank $12^{14}$ \\
\hline May 2008 & Transfer from Tank 51 to Tank $12^{14}$ \\
\hline
\end{tabular}


SRNL-STI-2008-00389

REVISION 0

Table 2: Tank 12 Supernate Sample Data Since Last Waste Receipt

\begin{tabular}{|c|c|c|c|c|c|c|c|}
\hline Sample Date & $\begin{array}{l}\text { Average } \\
(1975- \\
1981 \\
\text { samples) }\end{array}$ & $02 / 28 / 85$ & $11 / 29 / 84$ & $09 / 10 / 81$ & $04 / 01 / 80$ & $\begin{array}{c}12 / 18 / 7 \\
8\end{array}$ & $04 / 16 / 75$ \\
\hline Liquid Phase & & & & & & & \\
\hline Specific Gravity & - & EMPTY & 1.3680 & 1.4400 & 1.2000 & - & - \\
\hline Concentration in M: & & VIAL & & & & & \\
\hline $\begin{array}{l}\mathrm{Na}^{+} \text {(estimated from } \\
\text { charge balance) }\end{array}$ & 7.21 & & - & - & - & - & - \\
\hline $\mathrm{NO}_{2}^{-}$ & 1.60 & & 0.386 & 2.30 & 1.20 & 1.70 & 1.20 \\
\hline $\mathrm{NO}_{3}^{-}$ & 2.61 & & 0.415 & 3.10 & 2.90 & 1.45 & 3.00 \\
\hline $\mathrm{OH}^{-}$ & 1.42 & & 0.610 & 1.30 & 1.50 & 1.50 & 1.40 \\
\hline $\mathrm{Cl}^{-}$ & - & & - & - & - & - & - \\
\hline $\mathrm{SO}_{4}^{-}$ & 0.300 & & - & - & - & 0.300 & - \\
\hline $\mathrm{F}^{-}$ & - & & - & - & - & - & - \\
\hline $\mathrm{CO}_{3}^{-2}$ & 0.300 & & - & - & - & 0.300 & - \\
\hline $\mathrm{AlO}_{2}^{-}$ & 0.370 & & - & - & - & 0.300 & 0.440 \\
\hline $\mathrm{C}_{2} \mathrm{O}_{4}^{-2}$ & - & & - & - & - & - & - \\
\hline $\mathrm{PO}_{4}^{-3}$ & $<0.01$ & & - & - & - & $<0.01$ & - \\
\hline Gross Gamma (Ci/gal) & - & & - & - & - & - & - \\
\hline
\end{tabular}

\subsection{Tank 12 Supernate Concentration Due to Evaporation}

Monthly report data can be used to estimate the evaporation rates in tanks in a similar manner as Pike used in $1993^{15}$. Long periods of relatively quiescent times between transfers provide a reasonable length of time to average over several seasons and small, periodic maintenance flush water additions. Figure 2 graphically shows the monthly report data for the tank volumes and temperatures. 
SRNL-STI-2008-00389

REVISION 0

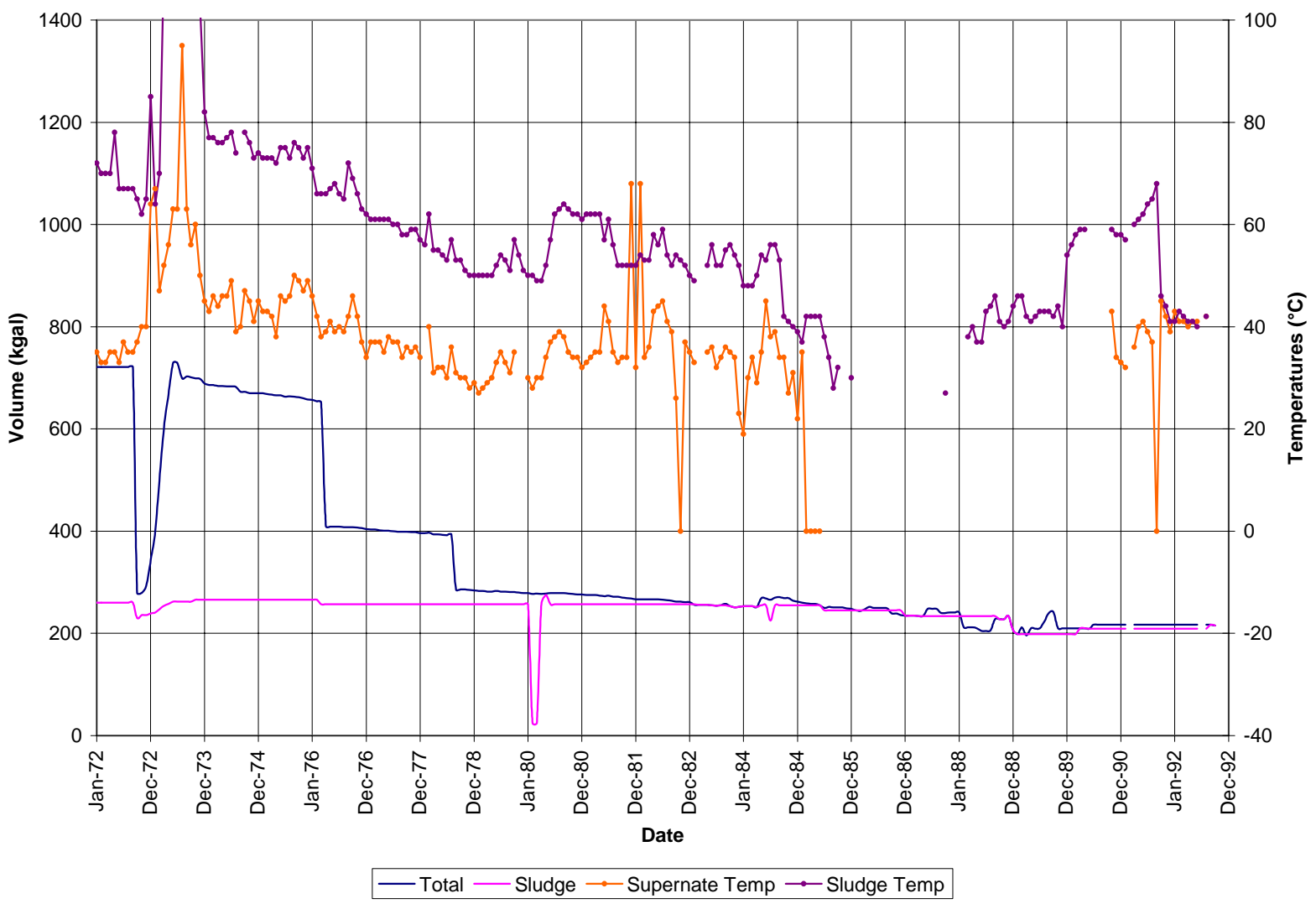

Figure 2: Tank 12 Volume and Temperature Data from Monthly Reports

Table 3 shows the evaporation rates estimated between transfers out of the tank. One might note that the evaporation rate appears to be decreasing as expected. However, once the liquid level falls below the surface, there's no way to track the changes. If one assumes that the evaporation rate maintains at a constant rate after the liquid level falls below the solids surface, then evaporation occurred at the volumetric equivalent rate of 2.1 inches per year until liquid addition in November 2004. 46.5" or 126,000 gallons of water is estimated to have evaporated since the last transfer, leaving 120,000 gallons of the equivalent original solution in the tank (note that 120,000 gallons in 176,000 gallons determined just before rewetting is not, in any way, "dry"). Since only water is removed due to evaporation, the concentration of the salts in solution actually increases inversely to the water content of the supernate.

Table 3: Tank 12 Evaporation Rates

\begin{tabular}{|c|c|c|}
\hline From & To & Evaporation (inches/year) \\
\hline $9 / 1978$ & $1 / 1983$ & 2.1 \\
\hline $4 / 1976$ & $8 / 1978$ & 2.7 \\
\hline $2 / 1974$ & $3 / 1976$ & 6.0 \\
\hline
\end{tabular}




\subsection{Absorption of Carbon Dioxide}

Carbon dioxide was measured at $361 \mathrm{ppm}$ in H-Area. ${ }^{16}$ Between the last transfer out of the tank in 1978 and liquid addition in 2004, 26.2 years at an estimated nominal $300 \mathrm{scfm}$ ventilation rate, Tank 12 supernate was exposed to 1.1 million moles of carbon dioxide. With an exposed liquid surface, practically all the carbon dioxide is absorbed by the liquid. However, it's not known how the rate is affected once the liquid surface falls below the top of the solids. Some amount of liquid is always wicking up to the surface of the solids. The water content of the solids increases with distance from the surface of the solids layer until the pores in the solids layer are completely full, thus, identifying the interstitial liquid level.

After the last transfer out of Tank 12 in $1978,105.5$ " or 286,000 gallons of waste remained containing an estimated $316,000 \mathrm{~kg}$ of sludge solids. Assuming a nominal sludge solid density of $2.40 \mathrm{~kg} / \mathrm{L}$, the total liquid volume was 251,000 gallons. At the average hydroxide concentration, Tank 12 contained a total of 1.4 million moles of free hydroxide. Therefore, Tank 12 has been exposed to nearly twice as much carbon dioxide as needed to completely deplete Tank 12 of free hydroxide. Note that carbon dioxide absorption progresses to an equilibrium near $\mathrm{pH}$ of 9-10. Therefore, it's likely that most if not all the free hydroxide was converted to carbonate and the hydroxide and carbonate are at or near equilibrium with the atmosphere. Further neutralization of metal hydroxides in the sludge solids may have occurred, converting the metal hydroxides to metal carbonates, but no further hydroxide depletion is assumed in this estimate.

\subsection{Radiolysis of Nitrate}

The conversion of nitrate to nitrite by radiolysis was measured in a waste tank at the rate of $4.9 \mathrm{E}-11$ moles/L/BTU of fission product heat. ${ }^{17}$ In order to estimate the total conversion of nitrate, the cumulative fission product heat generated between the 1978 transfer and the 2004 liquid addition needs to be estimated. The rate of fission product heat was tracked in monthly reports until the mid1990's. For the purposes of estimating the cumulative energy, periodic sampling of the heat generation rate was extracted from the monthly record and is shown in Table 4 and graphically in Figure 3. The rate of heat generation decreases as a unique function of the mixture of radio isotopes in the sludge waste and does not fit a function for a single average decay half life. For simplicity, the total decay heat was determined by numerically integrating the reported heat generation rate over time. The rate for each month between each extracted point is estimated by interpolation. Decay heat rate after the last reported rate is determined by linear extrapolation of the last two points. The cumulative decay heat is approximately 4.0E10 BTU, thus, the total nitrate to nitrite conversion is $2.0 \mathrm{moles} / \mathrm{L}$. 
SRNL-STI-2008-00389

REVISION 0

Table 4: Tank 12 Radiolytic Decay Heat Rate

\begin{tabular}{|c|c|l|c|}
\hline Date & $\begin{array}{c}\text { Radiolytic Decay } \\
\text { Heat Rate (BTU/hr) }\end{array}$ & \multicolumn{1}{|c|}{ Reference } & Page \\
\hline Feb-74 & $1,181,000$ & $\begin{array}{l}\text { Works Technical Department Report for February 1974, } \\
\text { DPSP 74-1-2, Redacted Version }\end{array}$ & 74 \\
\hline May-74 & 982,000 & $\begin{array}{l}\text { Works Technical Department Report for May 1974, } \\
\text { DPSP 74-1-5, Redacted Version }\end{array}$ & 85 \\
\hline Jul-74 & 879,534 & $\begin{array}{l}\text { Works Technical Department Report for July 1974, } \\
\text { DPSP 74-1-7, Redacted Version }\end{array}$ & 74 \\
\hline Oct-74 & 758,600 & $\begin{array}{l}\text { Works Technical Department Report for October 1974, } \\
\text { DPSP 74-1-10, Redacted Version }\end{array}$ & 69 \\
\hline Jan-75 & 665,303 & $\begin{array}{l}\text { Works Technical Department Report for January 1975, } \\
\text { DPSP 75-1-1, Redacted Version }\end{array}$ & 78 \\
\hline Dec-75 & 461,300 & $\begin{array}{l}\text { Works Technical Report for December 1975, DPSP 75- } \\
\text { 1-12, Redacted Version }\end{array}$ & S-46 \\
\hline Sep-76 & 348,300 & $\begin{array}{l}\text { Works Technical Report for September 1976, DPSP 76- } \\
\text { 1-9, Redacted Version }\end{array}$ & 63 \\
\hline Jan-79 & 250,000 & $\begin{array}{l}\text { Waste Management Programs Report for January 1979, } \\
\text { DPSP 79-21-1 }\end{array}$ & 25 \\
\hline Dec-80 & 229,400 & $\begin{array}{l}\text { Waste Management Programs Report for December } \\
\text { 1980, DPSP 80-21-12 }\end{array}$ & 25 \\
\hline Dec-92 & 167,700 & $\begin{array}{l}\text { High Level Waste Engineering Monthly Data Record, } \\
\text { WSRC-RP-92-78-12B, December 1992 }\end{array}$ & 12 \\
\hline
\end{tabular}

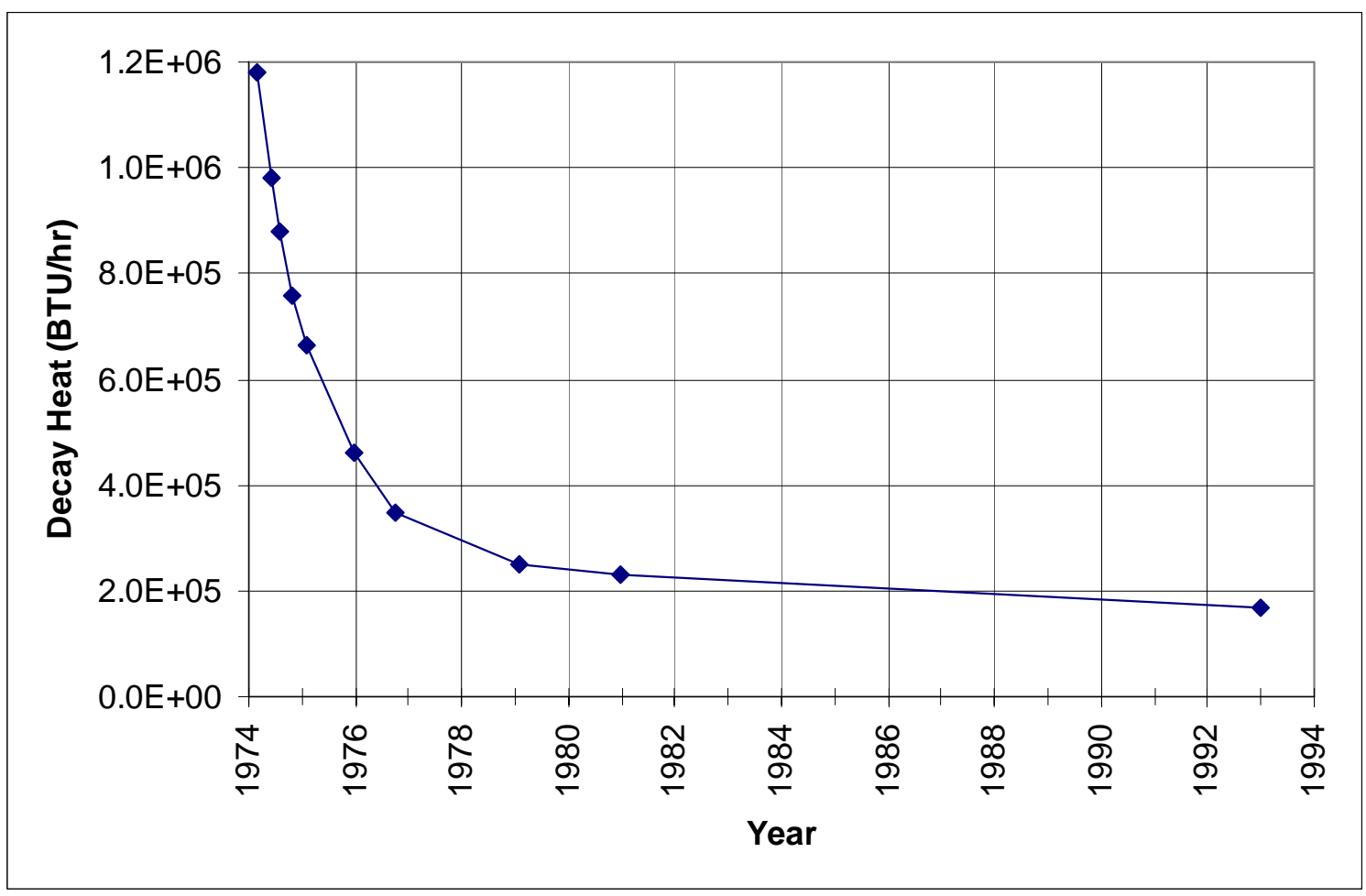

Figure 3: Tank 12 Radiolytic Decay Heat Estimation 


\subsection{Estimating Liquid Phase Composition}

After evaporation, carbon dioxide absorption, and nitrate conversion, the apparent composition of the liquid phase is shown in Table 6. This composition is not at equilibrium and will precipitate $2 \mathrm{Na}_{2} \mathrm{SO}_{4} \cdot \mathrm{Na}_{2} \mathrm{CO}_{3}$ (a carbonate-sulfate double salt), sodium carbonate monohydrate, and possibly a small amount of gibbsite. For this material balance, the extent of any precipitation was determined after accounting for the liquid additions.

Table 6 completes the material balance for Tank 12 up to the time sludge removal started. After liquid addition in 2004, some evaporation occurred. The apparent evaporation rate was 2.9 inches per year based on the waste level in Tank 12 before the supernate transfers from Tank 51 . This evaporation rate was very similar to the rates observed in the tank before the liquid level fell below the solids surface as shown in Table 3 .

After the transfers from Tank 51 to Tank 12, the reel tape was out of service for maintenance and put back in service indicating a somewhat lower level. The new level may be a result of recalibration, actual level change due to liquid "soaking" into the sludge layer, or evaporation. Regardless, the change was treated as evaporation since a volume reduction in the interstitial liquid by evaporation had to occur for any liquid to absorb into the sludge layer and the volume reduction was not previously accounted. The composition as of 6/30/2008 in the last column of Table 6 was used as the initial composition in Tank 12 for the aluminum dissolution material balance.

The final liquid composition is still not below saturation relative to $2 \mathrm{Na}_{2} \mathrm{SO}_{4} \cdot \mathrm{Na}_{2} \mathrm{CO}_{3}$, sodium carbonate monohydrate, and gibbsite. A relatively small volume of salt crystals remain in the waste. The aluminum dissolution material balance uses the apparent composition in order to account for the relative fraction of salt crystals carried in the slurry transfer to Tank 51.

The final estimate for Tank 12 initial composition is shown in Table 10.

\subsection{Estimating Solid Phase Composition}

The solids phase consists primarily of metal oxides and hydroxides that remain practically insoluble during aluminum dissolution. A small amount of mercury will dissolve with the aluminum, significantly increasing the mercury in solution, but the amount is small relative to the quantity of mercury in the sludge solids. ${ }^{3}$ As such all the components other than aluminum may be treated as inert mass and only the components associated with aluminum will change during dissolution. Therefore, only the aluminum content of the solid phase is tracked rigorously.

The aluminum content of the sludge is estimated from a recent sample of partially mixed sludge slurry in Tank 12. Table 5 shows the metals analysis for the Tank 12 sludge slurry sample and an estimate of the composition of the insoluble solids relative to an assumed solids species. The solids species were picked to be consistent with the LWO Waste Characterization System (WCS). ${ }^{14}$ However, WCS shows several forms of calcium and all the calcium is assumed to be in the form of calcium carbonate, the most likely form as predicted using OLI Stream Analyzer ${ }^{\mathrm{tm}}$. A few of the measured metals do not have equivalent solids tracked in WCS. Since these metals were measured at very low concentrations, they are assumed to make no significant contribution to the total mass and no equivalent compound assumed.

After conversion to the assumed chemical species, the composition was normalized to $100 \%$. 
Table 5: Aluminum Content Estimate of Tank 12 Sludge Solids

\begin{tabular}{|c|c|c|c|c|c|c|}
\hline \multicolumn{3}{|c|}{ Metals Analysis in Total Solids ${ }^{18}$} & \multicolumn{4}{|c|}{$\begin{array}{l}\text { Metals as Converted to Assumed Insoluble } \\
\text { Species }\end{array}$} \\
\hline Constituent & $\begin{array}{c}\text { MW } \\
\text { (g/mole) }\end{array}$ & $\begin{array}{l}\text { Mean } \\
\text { Concentration } \\
\text { Mass \% of TS }\end{array}$ & $\begin{array}{c}\text { Assumed } \\
\text { Insoluble } \\
\text { Chemical } \\
\text { Species }\end{array}$ & $\begin{array}{c}\text { MW } \\
\text { (g/mole) }\end{array}$ & $\begin{array}{c}\text { Mass \% } \\
\text { of IS }\end{array}$ & $\begin{array}{l}\text { Normalized } \\
\text { Mass \% of IS }\end{array}$ \\
\hline Al & 27 & 10 & $\mathrm{AlOOH}^{*}$ & 60.0 & 96 & 78.065 \\
\hline Ag & 107.9 & 0.0023 & $\mathrm{AgOH}$ & 124.9 & 0.0143 & 0.0117 \\
\hline B & & 0.009 & None & & & \\
\hline Ba & 137.3 & 0.013 & $\mathrm{BaSO}_{4}$ & 233.4 & 0.119 & 0.0972 \\
\hline Ca & 40.1 & 0.22 & $\mathrm{CaCO}_{3}$ & 100.1 & 2.96 & 2.41 \\
\hline Ce & 140.1 & 0.021 & $\mathrm{Ce}(\mathrm{OH})_{3}$ & 191.1 & 0.154 & 0.126 \\
\hline $\mathrm{Cr}$ & 52 & 0.036 & $\mathrm{Cr}(\mathrm{OH})_{3}$ & 103.0 & 0.384 & 0.314 \\
\hline $\mathbf{C u}$ & 63.6 & 0.01 & $\mathrm{Cu}(\mathrm{OH})_{2}$ & 97.6 & 0.0827 & 0.0675 \\
\hline $\mathbf{F e}$ & 55.6 & 1.0 & $\mathrm{Fe}(\mathrm{OH})_{3}$ & 106.6 & 10.3 & 8.43 \\
\hline Hg & 200.5 & 0.39 & $\mathrm{HgO}$ & 216.5 & 2.27 & 1.85 \\
\hline $\mathbf{K}$ & & 0.12 & $\begin{array}{l}\text { Assumed all } \\
\text { soluble }\end{array}$ & & & \\
\hline La & 138.9 & 0.011 & $\mathrm{La}(\mathrm{OH})_{3}$ & 189.9 & 0.0811 & 0.0661 \\
\hline Mg & 24.3 & 0.21 & $\mathrm{Mg}(\mathrm{OH})_{2}$ & 58.3 & 2.72 & 2.22 \\
\hline Mn & 54.9 & 0.47 & $\mathrm{MnO}_{2}$ & 86.9 & 4.01 & 3.27 \\
\hline Mo & & 0.0073 & None & & & \\
\hline $\mathrm{Na}$ & & 30 & $\begin{array}{l}\text { Assumed all } \\
\text { soluble }\end{array}$ & & & \\
\hline $\mathbf{N i}$ & 58.7 & 0.12 & $\mathrm{Ni}(\mathrm{OH})_{2}$ & 92.7 & 1.02 & 0.833 \\
\hline Pd & & 0.0018 & None & & & \\
\hline $\mathbf{R u}$ & 101.1 & 0.022 & $\mathrm{RuO}_{2}$ & 133.1 & 0.156 & 0.127 \\
\hline $\mathbf{R h}$ & & 0.0047 & None & & & \\
\hline Si & 28.1 & 0.04 & $\mathrm{SiO}_{2}$ & 60.1 & 0.461 & 0.376 \\
\hline $\mathrm{Sr}$ & 87.6 & 0.0069 & $\mathrm{SrCO}_{3}$ & 147.6 & 0.0627 & 0.0511 \\
\hline Th & 232 & 0.23 & $\mathrm{ThO}_{2}$ & 264 & 1.41 & 1.15 \\
\hline $\mathbf{T i}$ & 47.9 & 0.0029 & $\mathrm{TiO}_{2}$ & 79.9 & 0.0261 & 0.0213 \\
\hline $\mathbf{U}$ & 238 & 0.027 & $\mathrm{UO}_{2}(\mathrm{OH})_{2}$ & 304.0 & 0.186 & 0.152 \\
\hline Zn & 65.4 & 0.014 & $\mathrm{Zn}(\mathrm{OH})_{2}$ & 99.4 & 0.115 & 0.0936 \\
\hline $\mathrm{Zr}$ & 91.2 & 0.044 & $\mathrm{ZrO}(\mathrm{OH})_{2}$ & 125.2 & 0.326 & 0.266 \\
\hline Total & & 44.0 & & & 122.6 & 100.0 \\
\hline
\end{tabular}

* Aluminum concentration in insoluble solids was determined by subtracting the contribution of aluminum from the dissolved solids from the total solids. 
Mass percent in insoluble solids was calculated by the following conversion:

$$
\%_{\text {IS-Compound }}=\%_{\text {TS-Element }} \cdot \mathrm{MW}_{\text {Compound }} / \mathrm{MW}_{\text {Element }} \cdot \%_{\mathrm{TS}} / \%_{\mathrm{IS}}
$$

where

$\mathrm{MW}=$ molecular weight in $\mathrm{g} / \mathrm{mole}$,

$\%_{I S}=$ mass percent of insoluble solids in slurry, i.e., those solids not in the liquid phase of the sample, $7.2 \%,{ }^{19}$

$\%_{\mathrm{TS}}=$ mass percent of total solids in slurry, $38.8 \%,{ }^{19}$

$\%_{\text {IS-Compound }}=$ mass percent of compound in the insoluble solids, and

$\%_{\text {TS-Element }}=$ mass percent of element in the total solids.

A portion of the aluminum is in the dissolved solids such that the calculation includes the removal of soluble aluminum before converting as follows:

$\%_{\text {IS-Compound }}=\left(\%_{\text {TS-Element }} \cdot \rho_{\text {slurry }} \cdot \%_{\mathrm{TS}}-[\mathrm{Al}] \cdot \mathrm{MW}_{\text {Element }} / 1000 \mathrm{ml} / \mathrm{L}\right) /\left(\rho_{\text {slurry }} \cdot \%_{\text {IS }}\right) \cdot$

$\mathrm{MW}_{\text {Compound }} / \mathrm{MW}_{\text {Element }}$

where

$\rho_{\text {slurry }}=$ density of slurry, $\mathrm{g} / \mathrm{ml}, 1.35,{ }^{19}$ and

$[\mathrm{Al}]=$ concentration in supernate, $\mathrm{M}, 0.39 .^{20}$ 
Table 6: Tank 12 Composition Estimate

\begin{tabular}{|c|c|c|c|c|c|c|c|c|c|c|c|c|c|}
\hline Date & Sep-78 & & & & & $11 / 7 / 04-1 / 6 / 05$ & & & $4 / 6 / 2008$ & $5 / 5 / 2008$ & & & $6 / 30 / 2008$ \\
\hline Description & $\begin{array}{c}\text { Inventory } \\
\text { After Last } \\
\text { Transfer Out }\end{array}$ & $\begin{array}{c}\text { Estimated } \\
\text { Evaporative } \\
\text { Losses }\end{array}$ & $\begin{array}{c}\text { Tank } 12 \text { After } \\
\text { Evaporative } \\
\text { Loss }\end{array}$ & $\begin{array}{c}\text { Tank } 12 \\
\text { After CO2 } \\
\text { Absorbtion }\end{array}$ & $\begin{array}{c}\text { Tank } 12 \\
\text { After NO3 } \\
\text { Conversion }\end{array}$ & $\begin{array}{c}\text { Rewetting } \\
\text { Solution }\end{array}$ & $\begin{array}{c}\text { Evaporative } \\
\text { Loss After } \\
\text { Rewet }\end{array}$ & \begin{tabular}{|c|} 
Tank 12 \\
After \\
Evaporation
\end{tabular} & $\begin{array}{c}\text { Transfer A } \\
\text { from Tank } \\
51\end{array}$ & $\begin{array}{l}\text { Transfer B } \\
\text { from Tank } \\
51\end{array}$ & $\begin{array}{l}\text { Tank } 12 \\
\text { after } \\
\text { Transfers }\end{array}$ & $\begin{array}{c}\text { Water } \\
\text { Evaporation }\end{array}$ & $\begin{array}{c}\text { Tank } 12 \\
\text { after } \\
\text { Evaporation }\end{array}$ \\
\hline Tank Level, in & 105.5 & & \begin{tabular}{|r|}
59.0 \\
\end{tabular} & 59.0 & 59.0 & & 4.3 & 66.6 & & & 116.9 & & 109.8 \\
\hline $\begin{array}{l}\text { Total Volume, gal } \\
\text { wt\% Insoluble Solids } \\
\text { Total Mass, kg }\end{array}$ & 286,000 & $\begin{array}{l}126,000 \\
477,000\end{array}$ & 160,000 & 160,000 & 160,000 & 58,300 & 37,600 & 181,000 & $\begin{array}{r}32,100 \\
143,000\end{array}$ & $\begin{array}{r}88,700 \\
386,000\end{array}$ & $\begin{array}{r}317,000 \\
18.1 \% \\
1,747,000\end{array}$ & $\begin{array}{l}22,300 \\
84,400\end{array}$ & $\begin{array}{r}298,000 \\
19.0 \% \\
1,663,000\end{array}$ \\
\hline \multicolumn{14}{|l|}{ Liquid Phase } \\
\hline Volume, gal & 251,000 & 126,000 & 125,000 & 125,000 & 125,000 & 58,300 & 37,600 & 146,000 & 32,100 & 88,700 & 282,000 & 22,300 & 263,000 \\
\hline Sp G & - & 1.000 & - & - & - & - & - & - & 1.179 & 1.151 & 1.341 & 1.000 & 1.354 \\
\hline Mass of liquid, $\mathrm{kg}$ & - & 477,000 & - & - & - & - & - & - & 143,336 & 386,287 & $1,431,679$ & 84,414 & $1,347,264$ \\
\hline $\mathrm{Al}, \mathrm{kg}$ & 9,490 & - & 9,490 & 9,490 & 9,490 & - & - & 9,490 & 1,040 & 2,380 & 12,900 & - & 12,900 \\
\hline \multicolumn{14}{|l|}{ Concentration in M: } \\
\hline $\mathrm{Na}+$ & 7.21 & - & 14.53 & 14.53 & 14.53 & 3.50 & - & 13.87 & 3.92 & 3.30 & 8.75 & - & 9.39 \\
\hline NO2- & 1.60 & - & 3.21 & 3.21 & 5.17 & 1.20 & - & 4.91 & 0.410 & 0.376 & 2.71 & - & 2.90 \\
\hline NO3- & 2.61 & - & 5.24 & 5.24 & 3.29 & 1.10 & - & 3.26 & 0.410 & 0.351 & 1.84 & - & 1.98 \\
\hline $\mathrm{OH}-$ & 1.43 & - & 2.86 & - & - & 1.20 & - & 0.480 & 2.35 & 1.93 & 1.12 & - & 1.20 \\
\hline $\mathrm{Cl}-$ & & - & - & - & - & - & - & - & 0.0017 & 0.0015 & 0.0014 & - & 0.0015 \\
\hline SO4- & 0.300 & - & 0.602 & 0.602 & 0.602 & - & - & 0.517 & 0.0236 & 0.0213 & 0.277 & - & 0.297 \\
\hline F- & & - & & & & - & - & - & 0.0054 & 0.0048 & 0.0044 & - & 0.0047 \\
\hline $\mathrm{CO} 3-2$ & 0.300 & - & 0.602 & 2.033 & 2.033 & - & - & 1.74 & 0.313 & 0.265 & 1.02 & - & 1.09 \\
\hline AlO2- & 0.370 & - & 0.743 & 0.743 & 0.743 & - & - & 0.637 & 0.319 & 0.263 & 0.45 & - & 0.48 \\
\hline $\mathrm{C} 2 \mathrm{O} 4-2$ & & - & - & - & - & - & - & - & 0.0035 & 0.0036 & 0.0031 & - & 0.0034 \\
\hline PO4-3 & $<0.01$ & - & 0.020 & 0.020 & 0.020 & - & - & 0.017 & 0.0010 & 0.0009 & 0.0093 & - & 0.0100 \\
\hline $\mathrm{K}+$ & - & - & - & - & - & - & - & - & 0.0081 & 0.0068 & 0.0031 & - & 0.0033 \\
\hline \multicolumn{14}{|l|}{ Solid Phase } \\
\hline Sludge Solids Volume, gal & 34,800 & - & 34,800 & 34,800 & 34,800 & - & - & 34,800 & - & - & 34,800 & - & 34,800 \\
\hline Saltcake Volume, gal & - & - & - & - & - & - & - & - & - & - & - & - & 6,058 \\
\hline Sp G (bulk-hydrated) & 2.40 & - & 2.40 & 2.40 & 2.40 & - & - & 2.40 & - & - & 2.40 & - & 2.40 \\
\hline Saltcake Density, kg/L & - & - & - & - & 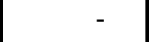 & - & - & - & - & - & - & - & 2.51 \\
\hline Mass of Insoluble Solids, & & & & & & & & & & & & & \\
\hline $\mathrm{kg}$, dried solids & 316,000 & - & 316,000 & 316,000 & 316,000 & - & - & 316,000 & - & - & 316,000 & - & 316,000 \\
\hline $\mathrm{wt} \% \mathrm{Al}$ in insoluble solids & $35.1 \%$ & - & $35.1 \%$ & $35.1 \%$ & $35.1 \%$ & - & - & $35.1 \%$ & - & - & $35.1 \%$ & - & $35.1 \%$ \\
\hline $\mathrm{Al}, \mathrm{kg}$ (as elemental $\mathrm{Al}$ ) & 110,900 & - & 110,900 & 110,900 & 110,900 & - & - & 110,900 & - & - & 110,900 & - & 110,900 \\
\hline Other Components, kg & 205,000 & - & 205,000 & 205,000 & 205,000 & - & - & 205,000 & - & - & 205,000 & - & 205,000 \\
\hline
\end{tabular}




\subsubsection{Tank 51 Composition}

Tank 51 is expected to have an 8" heel after preparation of sludge slurry for SB5. The initial composition shown in Table 10 was derived from the estimated composition after completion of sludge washing based the composition data from the waste qualification sample ${ }^{21,22}$ taken before washing was complete. The value for the aluminum content in insoluble solids can be derived from sample data as follows:

Solids per liter of supernate $=1 \mathrm{~L} \cdot 1.19 \mathrm{~kg} / \mathrm{L} \cdot 19.32 \mathrm{wt} \%$ dissolved solids $=0.230 \mathrm{~kg}$ solids $/ \mathrm{L}$

Aluminum in supernate: $7340 \mathrm{mg} / \mathrm{kg}$ supernate $\cdot 1.19 \mathrm{~kg}$ supernate $/ \mathrm{L} / 1000 \mathrm{mg} / \mathrm{g}=8.7346 \mathrm{~g} \mathrm{Al} / \mathrm{L}$

Weight fraction $\mathrm{Al}$ in supernate solids: $8.7346 \mathrm{~g} \mathrm{Al} / \mathrm{L} \cdot 1 \mathrm{~kg} / 1000 \mathrm{~g} / 0.230 \mathrm{~kg}$ solids $/ \mathrm{L}=0.0380$

Material balance per unit mass of slurry:

$(6.18 \mathrm{wt} \% \mathrm{Al}$ in total solids $) \cdot(23.61 \mathrm{wt} \%$ total solids in slurry $)=(3.80 \mathrm{wt} \% \mathrm{Al}$ in supernate solids $) \cdot(18.3$

$\mathrm{wt} \%$ soluble solids in slurry $)+(\mathrm{x} \mathrm{wt} \% \mathrm{Al}$ in insoluble solids $) \cdot(5.31 \mathrm{wt} \%$ insoluble solids in slurry $)$

Solving for $\mathrm{x}=14.4 \mathrm{wt} \% \mathrm{Al}$ in insoluble solids.

\subsubsection{Tank 8 Composition}

Tank 8 is expected to contain a heel as low as 2" before the transfer of aluminum-laden supernate into the tank for interim storage. Sludge waste was already removed from Tank 8 and is functioning as interim storage for waste removal activities in F-Tank Farm. Specifically, Tank 8 receives bulk supernate transfers from Tank 7 where the waste is sampled to qualify the waste for feed to the evaporator and is then transferred from Tank 8 to the evaporator feed tank. This sequence of transfers and sampling is planned to repeat at least 3 more times before aluminum-laden supernate will be transferred to Tank 8 . As such, the composition of the heel in Tank 8 will be very difficult to predict. Considering that the heel is relatively small compared to the aluminum-laden supernate planned to be transferred into Tank 8 , the effect of the heel will be small. Therefore, the composition is approximated from a similar solution rather than estimating the composition from a detailed material balance after a complex series of transfers, chemical additions, and reactions for the source of the supernate in Tank 7.

Tank 7 will receive spent oxalic acid cleaning solution from Tank 5 and Tank 6 and waste removal solutions from Tank 18 and Tank 19. Tank 8 received a transfer from Tank 7 on July 3, 2008, that consisted of neutralized and spent oxalic acid heel cleaning solutions. The composition of the liquid after the Tank 7 to Tank 8 transfer is used to estimate the composition of the heel. The supernate sample results from samples taken from Tank 8 shortly after the Tank 7 transfer are shown in Table 7. 
Table 7: Recent Tank 8 Sample Data ${ }^{23}$

\begin{tabular}{|l|l|c|c|}
\hline \multicolumn{1}{|c|}{ Date } & Average & $\begin{array}{c}07 / 09 / 08 \\
\text { Sample from } \\
\text { surface (125.3") }\end{array}$ & $\begin{array}{c}07 / 09 / 08 \\
\text { Sample from 6" } \\
\text { from bottom }\end{array}$ \\
\hline $\mathrm{Sp} \mathrm{G}$ & 1.2353 & 1.2152 & 1.2554 \\
$\begin{array}{l}\text { Concentration in M: } \\
\mathrm{Na}^{+} \text {(estimated from charge balance) }\end{array}$ & 4.83 & & \\
$\mathrm{NO}_{2}^{-}$ & 0.91 & 0.82 & 1.00 \\
$\mathrm{NO}_{3}^{-}$ & 0.93 & 0.82 & 1.03 \\
$\mathrm{OH}^{-}$ & 1.83 & 1.88 & 1.77 \\
$\mathrm{Cl}^{-}$ & 0.0073 & 0.0081 & 0.0064 \\
$\mathrm{SO}_{4}^{-}$ & 0.0631 & 0.0483 & 0.0779 \\
$\mathrm{~F}^{-}$ & - & - & - \\
$\mathrm{CO}_{3}^{-2}$ & 0.378 & 0.317 & 0.439 \\
$\mathrm{AlO}_{2}^{-}$ & 0.235 & 0.230 & 0.240 \\
$\mathrm{C}_{2} \mathrm{O}_{4}^{-2}$ & 0.0101 & 0.0115 & 0.0087 \\
$\mathrm{PO}_{4}^{-3}$ & 0.0069 & 0.0075 & 0.0062 \\
$\mathrm{Gross} \mathrm{Gamma} \mathrm{(Ci/gal)}^{-3}$ & 2.34 & 2.34 & - \\
\hline
\end{tabular}

\subsubsection{Tank 24 Composition}

Tank 24 supernate is planned for use in waste removal of Tank 12. Using an existing supernate rather than inhibited water reduces the amount of new water added to the tank farm which ultimately reduces the load on the evaporator. The supernate used in Tank 12 waste removal becomes the sludge interstitial liquid in Tank 51 for aluminum dissolution. The Tank 24 supernate contains free hydroxide and sodium salts that will supplement the caustic addition to Tank 51 for aluminum dissolution. The low aluminum content of the Tank 24 supernate is preferred over most existing supernates that contain significantly higher aluminum concentrations.

Samples of the existing Tank 24 supernate provide minimal data. Additional sample data can be obtained by tracing the history of the liquid to the origins of the liquid and extracting the closest sample data before transferring to Tank 24. Table 8 shows the history of transfers for the current supernate in Tank 24. The original source came from Tanks 38 and 43, but was first transferred into Tank 49 before transfer to Tank 24. No samples were taken from the liquid as it resided in Tank 49. A sample was taken from Tank 38 less than 10 days before the transfer from Tank 38 to Tank 49 as shown in Table 9. Part of the supernate came from Tank 43. However, the closest sample before the transfer from Tank 43 was about 2 months before in July and has minimal composition data. Comparison of the composition to the sample taken in May and October, shows the composition appears consistent with minimal changes, thus, the additional compositional data from these samples were averaged with the July sample to approximate the composition of the Tank 43 liquid. The composition of the liquid transferred into Tank 49 and eventually transferred to Tank 24 is then calculated by volume averaging the concentrations of the supernates from Tank 43 and Tank 38. Note that the supernate will be slightly diluted from the minimal heels in Tank 49 and again in Tank 24. The samples from Tank 24 show slight dilution for nitrate and nitrate and good agreement for specific gravity, but disproportionately low hydroxide concentration. Regardless, the estimated composition is formed by combining the Tank 24 sample data with the estimated transferred supernate. The minor constituents, potassium, oxalate, and phosphate, have no data available for estimating concentration and are ignored. 
Table 8: Historical Summary of Tank 24 Supernate

\begin{tabular}{|c|l|}
\hline June 23, 2004 & Tank 49 is emptied of existing liquid by transfer to Tanks 42 and 35 \\
\hline September 1, 2004 & 41,700 gallons of Tank 43 supernate is transferred into Tank 49 \\
\hline October 28, 2004 & 293,000 gallons of Tank 38 superante is transferred into Tank 49 \\
\hline November 16,2004 & 421,000 gallons of Tank 38 superante is transferred into Tank 49 \\
\hline March 1, 2005 & Tank 24 emptied of existing supernate by transfer to Tanks 21 and 22 \\
\hline $\begin{array}{c}\text { March 1, 2005 - } \\
\text { April 19, 2005 }\end{array}$ & $\begin{array}{l}784,000 \text { gallons of Tank 49 supernate is transferred into Tank 24, } \\
\text { effectively leaving Tank 49 empty. }\end{array}$ \\
\hline
\end{tabular}

Table 9: Tank 24 Supernate Composition Estimate

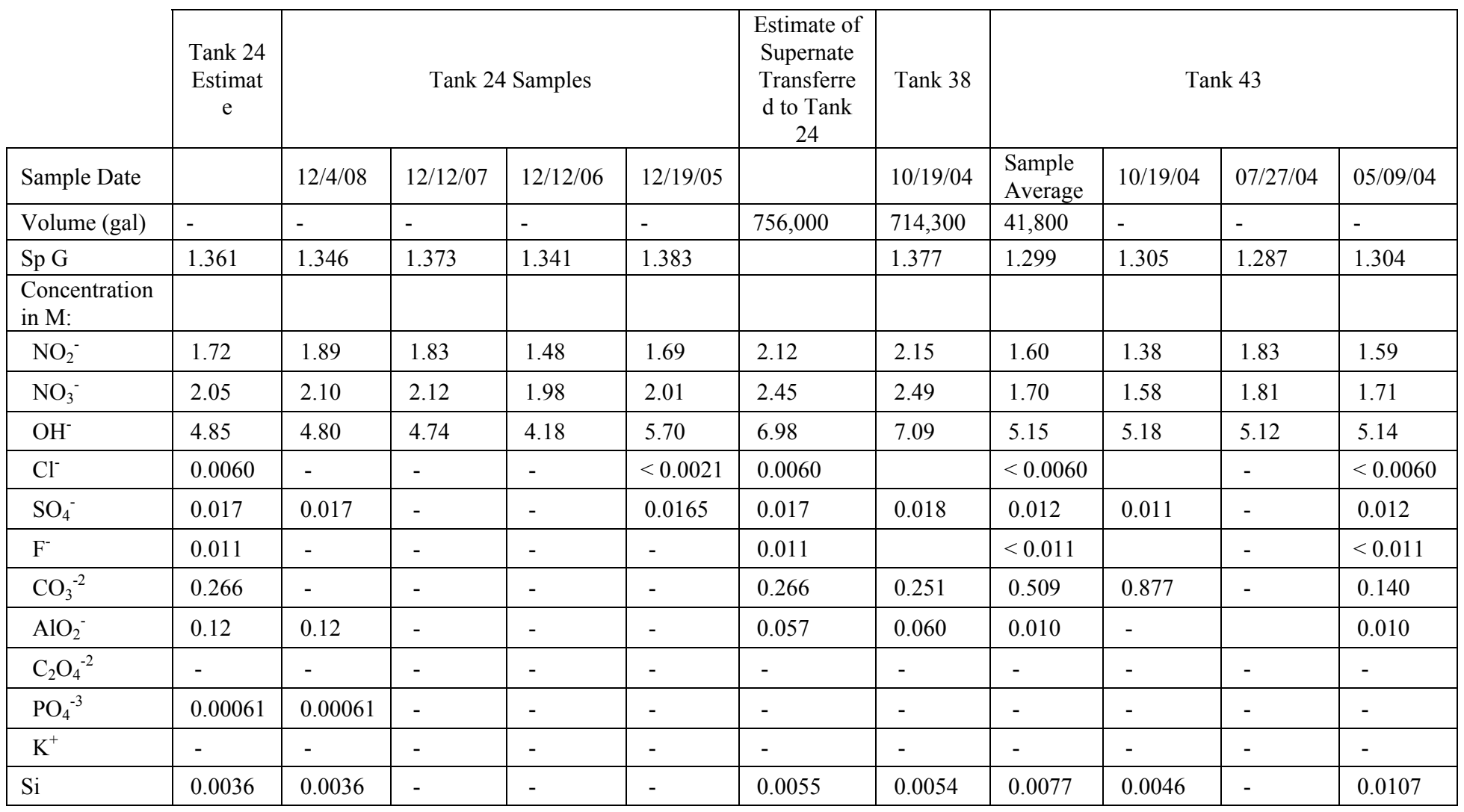

\subsubsection{Tank 4 Composition}

The total mass and aluminum content of the sludge solids in Tank 4 is based on the WCS using dial-up factors. $^{2}$ Half of this amount is slated for inclusion in SB6.

The supernate composition of Tank 4 is estimated from the latest historical samples from Tank 4 and Tank 8, and material balances for transfers between those tanks, dilution, evaporation, and burkeite dissolution in Tank 4 . The following sequence outlines the calculation resulting in the calculated initial supernate composition: 
1. A Tank 4 supernate sample from $11 / 20 / 01$ provided an initial $\left[\mathrm{PO}_{4}^{-3}\right]$ of less than $0.0053 \mathrm{M}$, an initial $\left[\mathrm{C}_{2} \mathrm{O}_{4}^{-2}\right]$ of less than 0.0058 , and an initial $\left[\mathrm{F}^{-}\right]$of less than 0.0053 .

2. Supernate analysis results from a Tank 4 VDS sample pulled on 5/12/05 provided an initial $\left[\mathrm{K}^{+}\right]$ of $0.065 \mathrm{M},\left[\mathrm{AlO}_{2}^{-}\right]$of $0.180 \mathrm{M}$, and a $\left[\mathrm{CO}_{3}^{-2}\right]$ of $0.510 \mathrm{M}^{24}$

3. An initial decant of supernate was made from Tank 4 to Tank 8 , followed by a series of four inhibited water additions, each of which was followed by a decant to Tank 33 . $^{25}$ Material balances were used to account for the dilution in Tank 4 and for the assumed uniform dissolution of the 6 inch burkeite layer. This provided updated estimates for concentrations of the species mentioned above.

4. Between April and September of 2007, a series of Tank 8 supernate transfers were made into Tank 4. That supernate receipt was a combination of the above supernate from Tank 4, and the previous contents of Tank 8 . The supernate in Tank 8 prior to the receipt of supernate from Tank 4 was characterized for the above species using Tank 8 samples:

$\begin{array}{llc}\text { Sample } & \text { Analysis } & \text { Concentration (M) } \\ 1 / 17 / 07 & {\left[\mathrm{AlO}_{2}^{-}\right]} & 0.217 \\ 1 / 17 / 07 & {\left[\mathrm{C}_{2} \mathrm{O}_{4}^{-2}\right]} & 0.016 \\ 10 / 18 / 06 & {\left[\mathrm{CO}_{3}^{-2}\right]} & 0.521 \\ 10 / 18 / 06 & {\left[\mathrm{PO}_{4}^{-3}\right]} & 0.0078\end{array}$

The results of the 10/18/06 sample were adjusted for apparent evaporation in Tank 8 over an extended period of time, to a $\left[\mathrm{CO}_{3}{ }^{-2}\right]$ of $0.548 \mathrm{M}$ and a $\left[\mathrm{PO}_{4}^{-3}\right]$ of $0.0082 \mathrm{M}$, respectively. Minor Tank 8 supernate species $\left[\mathrm{F}^{-}\right]$and $\left[\mathrm{K}^{+}\right]$were estimated at $0.012 \mathrm{M}$ and $0.033 \mathrm{M}$, respectively, from earlier samples and a more convoluted historical transfer accounting.

5. The current Tank 4 supernate composition estimate was obtained by material balance for the combination of the estimated Tank 4 and Tank 8 supernate compositions, and from two Tank 4 supernate samples as follows:

$\begin{array}{lll}\text { Sample } & \text { Analysis } & \text { Result } \\ 7 / 14 / 08 & \text { Sp.G. } & 1.321 \\ 7 / 14 / 08 & {\left[\mathrm{NO}_{2}^{-}\right]} & 1.66 \mathrm{M} \\ 7 / 14 / 08 & {\left[\mathrm{NO}_{3}^{-}\right]} & 1.86 \mathrm{M} \\ 7 / 14 / 08 & {\left[\mathrm{OH}^{-}\right]} & 1.44 \mathrm{M} \\ 1 / 14 / 08 & {\left[\mathrm{SO}_{4}^{-2}\right]} & 0.225 \mathrm{M} \\ 1 / 14 / 08 & {\left[\mathrm{Cl}^{-}\right]} & 0.016 \mathrm{M}\end{array}$

6. The Tank 4 slurry composition to be transferred to Tank 51 is estimated by assuming a single transfer, and accounting for enough additional water such that the transfer slurry $(50 \%$ of the Tank 4 insoluble solids) matches an estimated specific gravity of 1.25 , in accordance with the operating conditions of the Tank 4 submersible mixer pumps.

Table 10 summarizes the estimated initial conditions of Tanks 4, 8, 12, 24, and 51 at the start of aluminum dissolution. 
SRNL-STI-2008-00389

REVISION 0

Table 10: Initial Composition Estimates for Aluminum Dissolution of Sludge Batch 6

\begin{tabular}{|l|c|c|c|c|c|}
\cline { 2 - 6 } \multicolumn{1}{c|}{} & $\begin{array}{c}\text { Tank 4 } \\
\text { Slurry }\end{array}$ & $\begin{array}{c}\text { Tank 24 } \\
\text { Supernate }\end{array}$ & Tank 8 & Tank 12 & Tank 51 \\
\hline Initial Tank Level (in) & - & - & 4.0 & 109.8 & 8.0 \\
\hline Liquid Volume (gal) & - & - & 10,800 & 263,000 & 28,100 \\
\hline $\begin{array}{l}\text { Sludge Solids Volume } \\
\text { (gal) }\end{array}$ & - & - & - & 34,800 & 1,510 \\
\hline Insoluble Solids (kg) & 50,500 & - & - & 316,000 & 13,700 \\
\hline wt\% Insoluble Solids & 2.70 & 0 & 0 & 17.9 & 11.58 \\
\hline Specific Gravity & 1.234 & 1.361 & 1.235 & 1.354 & 1.044 \\
\hline Concentration in M: & & & & & \\
\hline $\mathrm{Na}^{+}$ & 4.85 & 9.33 & 4.83 & 9.39 & 1.00 \\
\hline $\mathrm{NO}_{2}^{-}$ & 1.21 & 1.72 & 0.91 & 2.90 & 0.233 \\
\hline $\mathrm{NO}_{3}^{-}$ & 1.35 & 2.05 & 0.93 & 1.98 & 0.096 \\
\hline $\mathrm{OH}^{-}$ & 1.05 & 4.85 & 1.83 & 1.20 & 0.460 \\
\hline $\mathrm{Cl}^{-}$ & 0.012 & 0.0060 & 0.0073 & 0.0015 & 0.0040 \\
\hline $\mathrm{SO}_{4}^{-}$ & 0.16 & 0.017 & 0.0631 & 0.297 & 0.0053 \\
\hline $\mathrm{F}^{-}$ & 0.0035 & 0.011 & - & 0.0047 & 0.0016 \\
\hline $\mathrm{CO}_{3}^{-2}$ & 0.39 & 0.266 & 0.378 & 1.10 & 0.066 \\
\hline $\mathrm{AlO}_{2}^{-}$ & 0.11 & 0.12 & 0.235 & 0.483 & 0.061 \\
\hline $\mathrm{C}_{2} \mathrm{O}_{4}^{-2}$ & 0.0039 & - & 0.0101 & 0.0034 & 0.0010 \\
\hline $\mathrm{PO}_{4}^{-3}$ & 0.0032 & 0.00061 & 0.0069 & 0.0100 & 0.00034 \\
\hline $\mathrm{K}^{+}$ & 0.036 & - & - & 0.0033 & 0.0020 \\
\hline
\end{tabular}

\subsubsection{Plutonium Waste Stream Receipts}

Two campaigns of plutonium waste stream receipts into Tank 51 during SB6 preparation are planned. The first campaign volume and composition are based on existing characterization data. ${ }^{26}$ The quantity and composition of the second, larger campaign has not been determined. In order to account for the effect on SB6 preparation, the total quantity of waste transferred into Tank 51 is assumed to correspond to $55 \mathrm{~kg}$ of plutonium. The composition is assumed to be the same as described for the SB5 Plutonium Discards received during SB5 preparation. $^{27}$

\subsubsection{Chemical Process Requirements}

LWO Planning, Integration, and Technology conducted a process study to determine process parameters that would result in removing $75 \%$ of the aluminum from the sludge slurry of the six target tanks. ${ }^{28}$ The method developed from this process study is applied to this flowsheet in order to determine dissolution conditions.

Without any additional constraints, the dissolution conditions chosen allow for the dissolution of up to $80 \%$ of the aluminum and for these solids to remain completely soluble at or below $20^{\circ} \mathrm{C}$. This condition minimizes the risk of precipitation of aluminum when Tank 51 sludge slurry is transferred into Tank 8 . The Tank 51 temperature is expected to be between 20 and $25^{\circ} \mathrm{C}$ during washing.

Figure 4 shows aluminum solubility at various temperatures. Isotherms are plotted for every $5^{\circ} \mathrm{C}$ generated from OLI Stream Analyzer ${ }^{\text {tm }}$ based the supernate chemistry after aluminum dissolution and dilution caused by bearing water leakage or flushing. The dotted red line shows the aluminum solubility 
estimated at $25^{\circ} \mathrm{C}$ for SB5 aluminum dissolution for comparison. Starting salt content of the SB5 supernate was substantially lower than planned for SB6. The operating conditions of the process are represented by connected red dots that meet the dissolution conditions outlined above. Using the initial conditions from section 4.2.1, the sludge slurry transferred from Tank 12 contains about 6.7 gal of liquid $/ \mathrm{kg}$ of aluminum. At the start of dissolution, the hydroxide concentration in Tank 51 needs to be about 5.3 M or greater as indicated by the point labeled " $0 \%$ Dissolved". This hydroxide concentration produces approximately 9:2 molar ratio of hydroxide to aluminum. About 102,000 gallons of $50 \mathrm{wt} \%$ caustic (19.1 M hydroxide) needs to be added to Tank 51 as shown in Section 4.7. Note that the caustic addition estimate is based on projections of the dissolution condition. The caustic addition estimate should be considered as the minimum caustic needed and is dependent on the actual composition of the waste slurry transferred from Tank 12, especially if more water is added to Tank 12 than expected during waste removal. Added water effectively reduces the starting free hydroxide concentration and ionic strength of the solution, potentially resulting in higher caustic demand to meet the same process conditions.

A sufficient margin below saturation of aluminum in Tank 8 supernate will be required throughout the time the solution is stored. At $80 \%$ dissolution of aluminum, the free hydroxide ion concentration will be adequate to maintain aluminum in solution as indicated by the point labeled "Tk 8 After Trans." in Figure 4. Some additional caustic may be needed during storage depending on total time stored in Tank 8 . Section 4.8.2.1 discusses the potential caustic additions needed for Tank 8 .

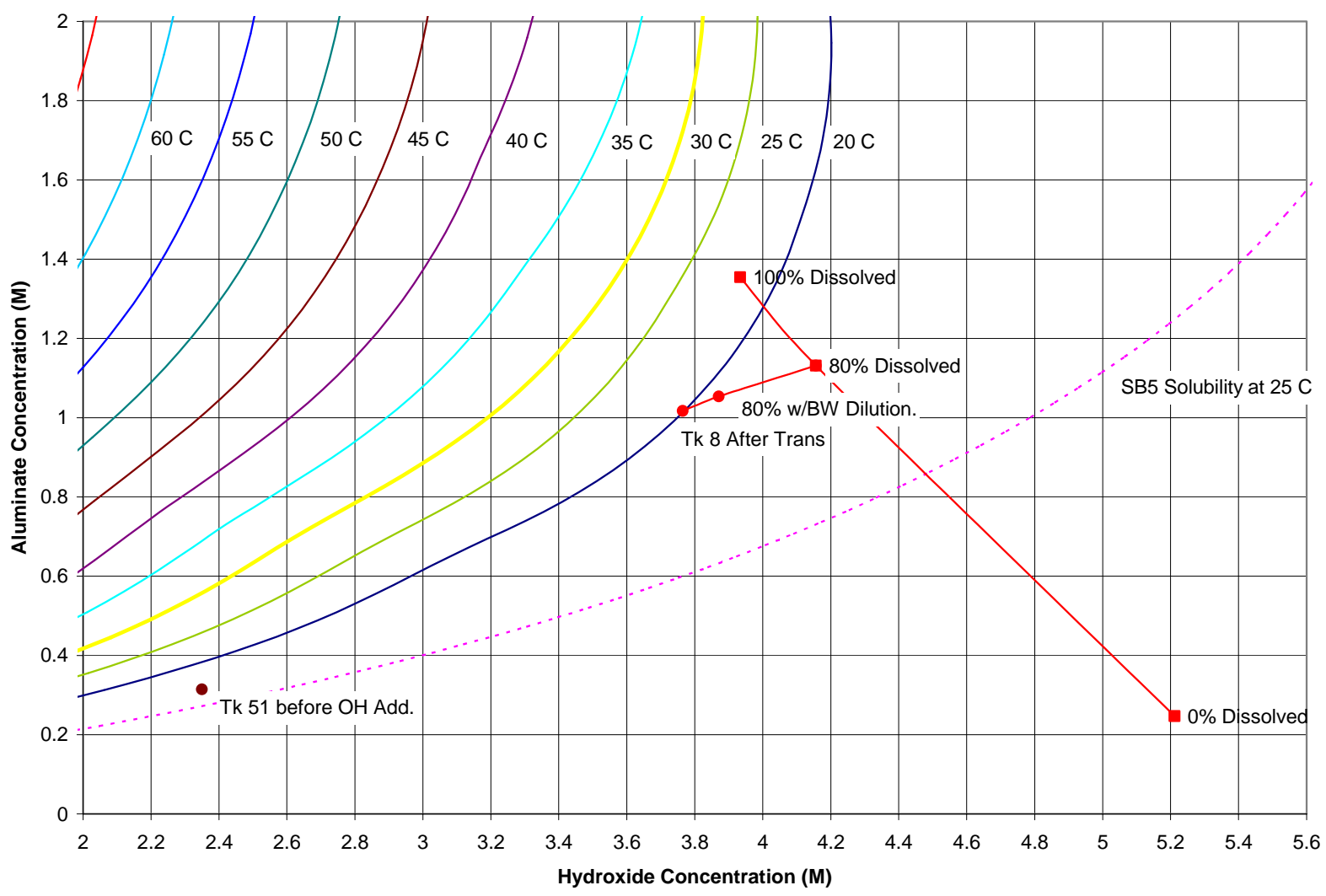

Figure 4: Dissolution Conditions for Sludge Batch 6 (based on gibbsite solubility) 
The high aluminum content of the leaching solution will precipitate aluminum when diluted. In order to prevent precipitation during washing, the first two wash water additions will need to be supplemented with adequate caustic to prevent precipitation. Figure 5 shows the approximate concentrations of the wash solutions superimposed on the same aluminum solubility curves shown in Figure 4, but for a lower range of hydroxide concentrations. Each wash composition is represented by a red square along a curve representing the washing conditions for the entire sludge batch preparation plan. With each wash water dilution, the solubility curves will tend to shift to the right, i.e., aluminum becomes progressively less soluble, but this set of isotherms provides a reasonable estimate of solubility, particularly in the first wash which affects most of the dissolved aluminum remaining in Tank 51. The first wash water addition includes adequate hydroxide for $1.2 \mathrm{M}$ hydroxide concentration. The second water addition is in the form of dilution water in Tank 4 to create a slurry that can be pumped between F-Tank Farm and H-Tank Farm. Adequate caustic should be added to Tank 51 to compensate for the dilution effect before the transfer from Tank 4 to equate to $1.0 \mathrm{M}$ hydroxide concentration in the water addition. These concentrations are adequate to minimize the risk of precipitation relative to the initial dissolution conditions, but ionic strength of the solution is diluted as well as the free hydroxide concentration, further reducing aluminum solubility. The aluminum solubility at the specific composition of each wash water batch will need to be calculated to provide the most accurate results.

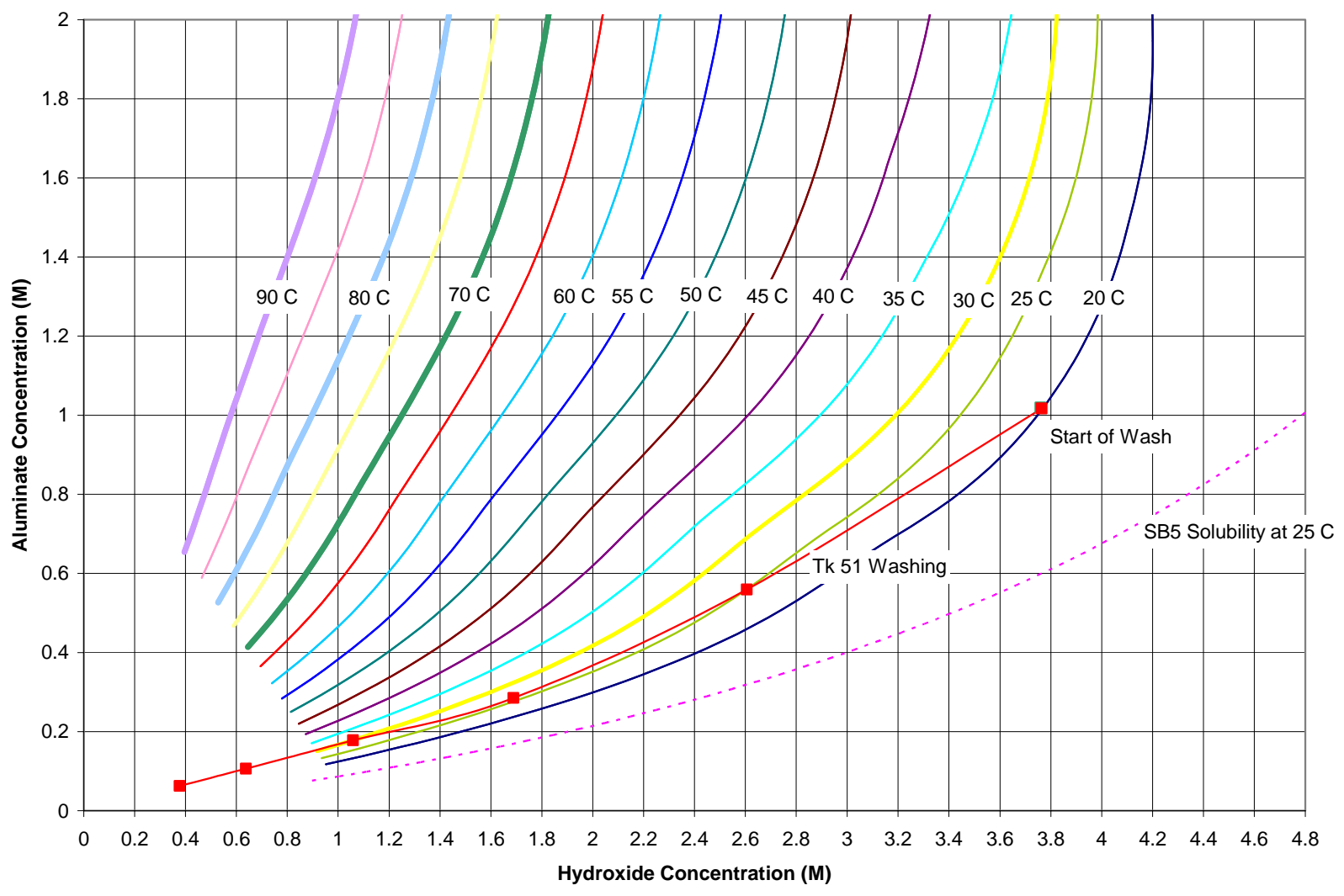

Figure 5: Sludge Washing Conditions for Sludge Batch 6 (based on gibbsite solubility)

The first wash solution will still contain substantial aluminum and is desirable to transfer to Tank 8 . Current plans include transfer of the first wash solution to Tank 8 . The mixture in Tank 8 as shown in the material balance in Section 4.7 is at or above saturation at less than $28^{\circ} \mathrm{C}$. To prevent precipitation down to $20^{\circ} \mathrm{C}$, hydroxide concentration will need to be maintained above $4.0 \mathrm{M}$. About 18,000 gallons of 
$50 \mathrm{wt} \%$ caustic would be needed for this. The need for caustic addition will need to be evaluated to prevent precipitation of aluminum after actual results of dissolution are known. The first wash decant would be transferred to the $3 \mathrm{H}$ evaporator system if not sent to Tank 8 .

\subsection{Temperature Change in Tank 51 Due to Caustic Addition}

Dilution of caustic in Tank 51 is strongly exothermic which tends to increase liquid temperature and the dissolution reaction is endothermic which tends to decrease liquid temperature. Since the dissolution reaction is slow relative to the rate of transfer of hydroxide solution into Tank 51, the reaction will tend to slowly absorb the heat generated from the initial heat generated from dilution. The caustic solution transfer from HPT-7 and HPT-8 will occur in small batches, 3000 gal each, over approximately 3 weeks. The duration of each transfer will be short. The dissolution reaction will continue for many days after the last transfer is complete. The maximum temperature increase expected is estimated using OLI Stream Analyzer ${ }^{\mathrm{tm}}$. The planned caustic addition combined with the composition of the liquid shown in Section 4.7 results in a $10^{\circ} \mathrm{C}$ increase. The temperature of the tank contents will be closely monitored during the transfer and subsequent dissolution process.

\subsection{Process Cycle Time}

Table 11 outlines the process steps and estimated time required to complete each step. The basis for the settling time is discussed in Section 4.6.

Table 11: Process Cycle Time (with no down time)

\begin{tabular}{|l|c|}
\hline Step & Time (days) \\
\hline $\begin{array}{l}\text { Add caustic to Tank 51 via HPT-7 and HPT-8 (108,000 } \\
\text { gallons = 36 3000-gallon trucks @ 3 per day). }\end{array}$ & 12 \\
\hline Use slurry pumps to increase tank temperature and maintain. & N/A \\
\hline $\begin{array}{l}\text { Mix tank for number of days available (duration currently } \\
\text { scheduled). }\end{array}$ & N/A \\
\hline Turn off slurry pumps to allow settling. & 30 \\
\hline Settle for 30 days. & 5 \\
\hline $\begin{array}{l}\text { Decant aluminum-laden supernate to decant storage tank, } \\
\text { Tank 8. (350,000 gal @ 50 gpm) }\end{array}$ & $\mathbf{7 5}$ days \\
\hline Total Cycle Time in Tank 51 & \\
\hline
\end{tabular}

Note that caustic additions are planned for normal facility 4 day work week and no more than 12 per week. Accounting for weekends, the caustic addition may take about 18 calendar days to complete. Adding 2 week ends results in a total cycle time of about 81 days. The remaining operations can occur without breaks.

Note that the time for mixing the tank is not optimal, but reflects scheduled days available. Section 4.5 discusses optimal time for completing aluminum dissolution. 


\subsection{Extent of Aluminum Dissolved}

\subsubsection{Caustic Dissolution Kinetics}

Gibbsite and boehmite are common forms of aluminum in HLW sludge. Boehmite is the thermodynamically favored form of aluminum such that gibbsite will tend to convert to boehmite over time. Given that the last waste receipt to Tank 12 was from June 1973, much of the aluminum is likely to be boehmite as was the case in Tank $11 .^{29}$ Consistent with the strategy developed for aluminum dissolution $^{28}$ all the aluminum is assumed to be the form of boehmite.

The model was solved numerically to determine fraction dissolved with time. At $70^{\circ} \mathrm{C}, 85$ days are required to achieve $80 \%$ dissolution. At $75^{\circ} \mathrm{C}, 46$ days are required. The result for 28 days shows $42 \%$ of the aluminum dissolves at $70^{\circ} \mathrm{C}$ and $63 \%$ at $75^{\circ} \mathrm{C}$. If the dissolution rate turns out to be as fast as the sludge slurry from Tank $11,80 \%$ dissolution can be achieved in 24 days at $70^{\circ} \mathrm{C}$. The amount dissolved is sensitive to the temperature. Maintaining the waste as warm as practical during the dissolution cycle will dissolve the most aluminum. For this material balance, the maximum of $80 \%$ dissolved is carried throughout in order to identify adequate process conditions to achieve the most dissolution possible. 55\% dissolution of the aluminum is a reasonable nominal expectation if the time is not available to reach $80 \%$ dissolution, with a total potential range from $40-80 \%$.

\subsection{Process Constraints and Assumptions}

Other than physical limitations, the process is constrained by maximum temperature allowed in Tank 51 and the amount of time allowed for sludge settling prior to each decant. Assumptions for each of these constraints are identified in separate sections below along with assumptions related to the material balance. Any assumptions applied to initial composition and conditions are detailed in Section 4.2.1.

\subsubsection{Tank Temperature}

The constraints and assumptions that tank temperature limits are as follows:

- After caustic addition, the corrosion control program will limit tank temperature to less than $100^{\circ} \mathrm{C}$ for the liquid and sludge slurry. The tank wall will be limited to $95^{\circ} \mathrm{C} .^{30}$

- A requisite quantity of sodium nitrite is added during washing before the hydroxide supernate concentration drops below $1.0 \mathrm{M}^{30}$

- Vapor load at process temperatures remains within the capacity of the ventilation system.

\subsubsection{Settling Time Allowance}

The following must be completed within the available quiescent time in Tank 51 specified per the Flammability Control Program criteria: ${ }^{31}$

- Settling prior to decant of supernate from Tank 51,

- turbidity height measurement,

- decant jet repositioning,

- decant transfer, and 
- initiation of slurry pump to reset the quiescent time clock.

The constraints and assumptions that drive settling time and quiescent time management are as follows:

- Available settling time is calculated from the quiescent time less 7 days. The 7 days is an allowance for turbidity check, jet positioning, decant, and initiation of slurry pump run.

- $\quad 50 \%$ flammable gas retention is assumed for conditions where the sludge is projected to settle to less than 90" height in 20 days. This is in accordance with the Flammability Control Program. ${ }^{31}$

- $100 \%$ flammable gas retention is assumed for before aluminum dissolution and when settling from a very high initial slurry height, such that a sludge height of less than 90 " in 20 days is not expected.

- Initial sludge and supernate radiolytic heats, are based on the WCS. ${ }^{14}$

\subsubsection{Settling}

The rate of change to the level of sludge solids drives the maximum size of a decant within the constraint of the available quiescent time. The constraints and assumptions that drive settling are as follows:

- Tank 51 solids settling rates are projected from historical observation of SB4 and SB5 settling in Tank 51.

- Pre-dissolution sludge is projected to settle like Sludge Batch 4 sludge and pre-dissolution SB5 sludge, ${ }^{32}$ adjusting for the projected solids mass.

- Post-dissolution sludge settling behavior is projected from SB5 post-dissolution settling results as follows:

The SB5 post-dissolution sludge was modeled by empirically adjusting the sludge mass input of the pre-dissolution model to match observed behavior of the SB5 post dissolution sludge.

The actual mass reduction by dissolution of SB5 per analyses was compared to the "apparent" mass reduction that satisfied the settling model. The ratio of these two masses was applied to the planned SB6 dissolved mass, in order to obtain an adjusted mass input value for the SB6 post dissolution settling model.

- Tank 4 sludge settling is modeled using the historical settling model for PUREX sludge slurry. ${ }^{33}$ An "infinite settled height" input to the model was estimated by assuming that the sludge mass in Tank 4 will settle to a compaction of $280 \mathrm{~g}$ solids per liter of settled slurry in 20 days.

- The settling of the combined post-dissolution sludge and Tank 4 sludge was modeled by assuming that the two sludge slurries behave independently, and using a technique described in reference 32.

\subsubsection{Material Balance Assumptions and Constraints}

The constraints and assumptions that apply to the material balance and are not identified elsewhere are as follows:

- Sludge additions to Tank 51 include approximately $56 \%$ of the sludge in Tank 12 , and $50 \%$ of the sludge in Tank 4. 
- Sludge solids are assumed to have a density of $2.4 \mathrm{~g} / \mathrm{ml}$. This assumption is used to estimate supernate volumes within a sludge slurry.

- Tank 12 maximum fill limit is 120 inches.

- Liquid transfers into Tank 12 are limited to allow for 5" operating margin below the maximum fill limit.

- Tank 51 waste level is limited to 12 " below the high level liquid conductivity probe set point. The set point will be altered as necessary to maintain adequate quiescent time.

- A 12 inch separation between the decanting jet and the measured turbidity level is maintained during initial decant to Tank 8 and the final wash decant, based on Reference ${ }^{34}$

- A 24 inch separation between the decanting jet and the measured turbidity level is maintained during other decants to the evaporator systems.

- The first wash decant volume to Tank 8 is 150,000 gallons.

- The second wash decant volume to the $3 \mathrm{H}$ Evaporator system is 120,000 gallons.

- Wash decants after the first two are sent to the $2 \mathrm{~F}$ Evaporator system.

- The first decant to the 2F Evaporator system is 300,000 gallons.

- Decants to the 2F Evaporator after the first decant are limited by the time estimated to process the previous decant. The decant limit is estimated as follows:

o The initial decant fills the feed tank

o Subsequent decant fills the volume recovered by evaporation since the last decant.

o The time for processing is estimated as four days longer than the settling time of immediately before the planned decant, i.e., the time between decants is estimated as the settling time plus 4 days.

0 The $2 \mathrm{~F}$ evaporator is assumed to process 7,020 gallons ( 2 inches) per day.

- Slurry transfers from Tank 12 are $8.0 \mathrm{wt} \%$ insoluble solids.

- The Tank 4 sludge removal for SB6 is accomplished in a single transfer after dilution with water to dilute the slurry specific gravity to 1.25 .

- The washing end point is assumed to be $1.0 \mathrm{M}$ sodium in the supernate. The end point will change as detailed characterization data becomes available and DWPF flowsheet testing is completed.

\subsection{Material Balance}

A material balance for the aluminum dissolution process using the process parameters outlined above is shown in Table 12. The material balance includes the composition of the SB6 slurry, the number of decants, and the size of decants needed to complete the batch washing in Tank 51. The washing projection was performed by using a series of sequential material balances in Excel spreadsheet form to describe the steps for stepwise dilution, settling, and decanting of the supernate from the resultant slurry until the target feed composition for DWPF is reached. The same process is used in preparing the sludge batch plan. The following key points result from the material balance: 
1. Incorporating aluminum dissolution into SB6 preparation at the maximum extent of dissolution results in $130,000 \mathrm{~kg}$ of washed insoluble sludge solids in Tank 51, at an insoluble solids concentration of approximately $11 \mathrm{wt} \%$. In comparison, the SB6 base case (without aluminum dissolution) results in $244,000 \mathrm{~kg}$ of insolubles.

2. Washing of SB6 with aluminum dissolution requires an initial decant from Tank 51 to remove aluminum-laden supernate. In this study, a single initial decant volume was maximized at 354,000 gallons. However, this decant should be as large as possible. Maximizing the decant:

- reduces the potential for aluminum reprecipitation in SB6,

- reduces the subsequent degree of washing needed, and

- marginally improves washing efficiency.

Washing efficiency marginally improves because the proportion of nitrites and nitrates increases relative to hydroxide in the supernate, suppressing hydrogen generation and incrementally increasing available settling times. In addition, less hydroxide is needed in the wash water to minimize reprecipitation.

3. The level in Tank 8 after the post-dissolution decant is about 135".

4. Continued storage of the aluminum-laden supernate will require monitoring of the anion concentrations to assure hydroxide concentration is maintained such that the aluminum remains in solution.

Salient streams from Table 12 are depicted in Figure 6, which summarizes the material balance. This material balance includes the downstream impacts of sludge washing, but does not include any impact on DWPF or the evaporator. Existing evaporator processes ${ }^{35,36}$ can be used to model the respective portions of the flowsheet. Figure 6 summarizes the overall material balance for aluminum.

Water additions from miscellaneous flushes are not accounted in this material balance; however, the additions are not expected to have a significant effect. An allowance for slurry pump bearing water leakage is included at a nominal rate of 1200 gallons per day for a total of 40 days which allows for an additional 12 day buffer beyond what is scheduled. The buffer was added to provide a small amount of conservatism in the composition estimate relative to aluminum solubility after aluminum dissolution. The leak rate is based on the rate observed during the last 12 days of running pumps during dissolution on SB5, which was 1140 gallons per day. 
Table 12: Material Balance

(assuming $80 \%$ of the aluminum dissolves)

\begin{tabular}{|c|c|c|c|c|c|c|c|c|c|c|c|c|c|}
\hline Stream No & 1 & 2 & 3 & 4 & 5 & 6 & 7 & 8 & 9 & 10 & 11 & 12 & 13 \\
\hline Description & \begin{tabular}{|c} 
Initial Tank \\
51 \\
Inventory \\
\end{tabular} & \begin{tabular}{|c|}
$\mathrm{Pu}$ \\
Transfers to \\
Tank 51 \\
\end{tabular} & $\begin{array}{c}\text { Tank } 51 \\
\text { Inventory } \\
\text { After Pu } \\
\text { Transfer } \\
\end{array}$ & $\begin{array}{c}\text { Initial } \\
\text { Tank } 12 \\
\text { Inventory } \\
\end{array}$ & \begin{tabular}{|c} 
Tank 12 to \\
51 Transfer \\
$\mathrm{A}$
\end{tabular} & $\begin{array}{c}\text { Tank } 12 \\
\text { Inventory } \\
\text { After } \\
\text { Transfer A } \\
\end{array}$ & $\begin{array}{c}\text { Tank } 51 \\
\text { Inventory } \\
\text { After Tk } 12 \\
\text { Transfer A } \\
\end{array}$ & $\begin{array}{c}\text { Water } \\
\text { Addition } \\
\text { to Tank } \\
12 \\
\end{array}$ & $\begin{array}{c}\text { Tank } 24 \\
\text { to Tank } \\
12 \\
\text { Transfer } \\
\end{array}$ & $\begin{array}{c}\text { Tank } 12 \\
\text { Inventory } \\
\text { After Tank } \\
24 \text { Transfer } \\
\end{array}$ & \begin{tabular}{|c} 
Tank 12 to \\
51 Transfer \\
$\mathrm{B}$ \\
\end{tabular} & $\begin{array}{c}\text { Tank } 12 \\
\text { Inventory } \\
\text { After } \\
\text { Transfer B } \\
\end{array}$ & $\begin{array}{c}\text { Tank } 51 \\
\text { Inventory } \\
\text { After Tk } 12 \\
\text { Transfer B } \\
\end{array}$ \\
\hline Tank Level, in & 8.0 & & 9.1 & 109.8 & & 49.7 & 54.5 & & & 115.0 & & 30.9 & 119.7 \\
\hline Total Volume, gal & 28,100 & 3,500 & 31,900 & 298,000 & 163,000 & 135,000 & 191,000 & 20,000 & 157,000 & 312,000 & 228,000 & 83,700 & 420,000 \\
\hline wt \% Insoluble Solids & $11.58 \%$ & $1.51 \%$ & $10.34 \%$ & $18.99 \%$ & $8.00 \%$ & $30.92 \%$ & $8.32 \%$ & $0.00 \%$ & $0.00 \%$ & $14.67 \%$ & $8.00 \%$ & $30.93 \%$ & $8.14 \%$ \\
\hline Total Mass, $\mathrm{kg}$ & 119,000 & 16,700 & 135,000 & $1,663,000$ & 866,000 & 798,000 & $1,001,000$ & 76,000 & 807,000 & $1,680,000$ & $1,192,000$ & 489,000 & $2,192,000$ \\
\hline \multicolumn{14}{|l|}{ Liquid Phase } \\
\hline Volume, gal & 26,600 & 3,470 & 30,300 & 263,000 & 155,000 & 108,000 & 182,000 & 20,000 & 157,000 & 285,000 & 218,000 & 67,000 & 400,000 \\
\hline $\mathrm{Sp} \mathrm{G}$ & 1.044 & 1.250 & 1.058 & 1.354 & 1.354 & 1.354 & 1.332 & 1.000 & 1.361 & 1.331 & 1.331 & 1.331 & 1.328 \\
\hline Mass of liquid, $\mathrm{kg}$ & 105,000 & 16,400 & 121,000 & $1,347,000$ & 796,000 & 551,000 & 918,000 & 76,000 & 807,000 & $1,434,000$ & $1,096,000$ & 338,000 & $2,014,000$ \\
\hline $\mathrm{Al}, \mathrm{kg}$ & 166 & 0.0 & 166 & 12,900 & 7,640 & 5,290 & 7,810 & 0 & 1,922 & 7,210 & 5,510 & 1,700 & 13,316 \\
\hline \multicolumn{14}{|l|}{ Concentration in M: } \\
\hline $\mathrm{Na}+$ & 1.00 & 4.58 & 1.40 & 9.39 & 9.39 & 9.39 & 8.25 & 0.00 & 9.33 & 8.69 & 8.69 & 8.69 & 8.47 \\
\hline NO2- & 0.23 & 0.003 & 0.20 & 2.90 & 2.90 & 2.90 & 2.51 & 0.00 & 1.72 & 2.05 & 2.05 & 2.05 & 2.25 \\
\hline NO3- & 0.096 & 3.35 & 0.47 & 1.98 & 1.98 & 1.98 & 1.77 & 0.00 & 2.05 & 1.88 & 1.88 & 1.88 & 1.82 \\
\hline OH- & 0.46 & 1.20 & 0.54 & 1.20 & 1.20 & 1.20 & 1.12 & 0.00 & 4.85 & 3.13 & 3.13 & 3.13 & 2.21 \\
\hline $\mathrm{Cl}-$ & 0.0040 & 0.004 & 0.0039 & 0.0015 & 0.0015 & 0.0015 & 0.0019 & 0.00000 & 0.00600 & 0.00387 & 0.00387 & 0.00387 & 0.0030 \\
\hline SO4- & 0.0053 & 0.00182 & 0.0049 & 0.30 & 0.30 & 0.30 & 0.25 & 0.000 & 0.017 & 0.12 & 0.12 & 0.12 & 0.18 \\
\hline F- & 0.0016 & 0.013 & 0.0029 & 0.0047 & 0.0047 & 0.0047 & 0.0045 & 0.0000 & 0.0111 & 0.0079 & 0.0079 & 0.0079 & 0.0063 \\
\hline $\mathrm{CO} 3-2$ & 0.066 & 0.00283 & 0.058 & 1.09 & 1.09 & 1.09 & 0.94 & 0.000 & 0.266 & 0.56 & 0.56 & 0.56 & 0.73 \\
\hline $\mathrm{AlO} 2-$ & 0.061 & 0.000 & 0.054 & 0.48 & 0.48 & 0.48 & 0.42 & 0.000 & 0.120 & 0.25 & 0.25 & 0.25 & 0.33 \\
\hline $\mathrm{C} 2 \mathrm{O} 4-2$ & 0.0010 & 0.0000 & 0.0009 & 0.0034 & 0.0034 & 0.0034 & 0.00302 & 0.0000 & 0.0000 & 0.0013 & 0.0013 & 0.0013 & 0.0021 \\
\hline PO4-3 & 0.00034 & 0.0000 & 0.00030 & 0.0100 & 0.0100 & 0.0100 & 0.0086 & 0.00000 & 0.00061 & 0.0041 & 0.0041 & 0.0041 & 0.0061 \\
\hline $\mathrm{K}+$ & 0.0020 & 0.0000 & 0.0018 & 0.0033 & 0.0033 & 0.0033 & 0.0031 & 0.0000 & 0.0000 & 0.0012 & 0.0012 & 0.0012 & 0.0021 \\
\hline \multicolumn{14}{|l|}{ Solid Phase } \\
\hline Volume, gal & 1,510 & 28 & 1,540 & 34,800 & 7,620 & 27,100 & 9,160 & 0 & 0 & 27,100 & 10,492 & 16,600 & 19,700 \\
\hline Sp G (bulk-hydrated) & 2.40 & 2.40 & 2.40 & 2.40 & 2.40 & 2.40 & 2.40 & 2.40 & 2.40 & 2.40 & 2.40 & 2.40 & 2.40 \\
\hline $\begin{array}{l}\text { Mass of Insoluble Solids, kg, dried } \\
\text { solids }\end{array}$ & 13,700 & 251 & 14,000 & 316,000 & 69,200 & 247,000 & 83,200 & 0 & 0 & 247,000 & 95,300 & 151,000 & 179,000 \\
\hline $\mathrm{wt} \% \mathrm{Al}$ in insoluble solids & $14.4 \%$ & $0.0 \%$ & $14.1 \%$ & $35.1 \%$ & $35.1 \%$ & $35.1 \%$ & $31.6 \%$ & $0.0 \%$ & $0.0 \%$ & $35.1 \%$ & $35.1 \%$ & $35.1 \%$ & $33.5 \%$ \\
\hline $\mathrm{wt} \%$ as $\mathrm{Al}(\mathrm{OH}) 3$ in insoluble solids & $41.6 \%$ & $0.0 \%$ & $40.9 \%$ & $101 \%$ & $101 \%$ & $101 \%$ & $91 \%$ & $0.0 \%$ & $0.0 \%$ & $101 \%$ & $101 \%$ & $101 \%$ & $97 \%$ \\
\hline $\mathrm{wt} \%$ as $\mathrm{AlO}(\mathrm{OH})$ in insoluble solids & $32.0 \%$ & $0.0 \%$ & $31.4 \%$ & $78.1 \%$ & $78.1 \%$ & $78.1 \%$ & $70.2 \%$ & $0.0 \%$ & $0.0 \%$ & $78.1 \%$ & $78.1 \%$ & $78.1 \%$ & $74.4 \%$ \\
\hline $\mathrm{Al}, \mathrm{kg}$ (as elemental $\mathrm{Al})$ & 1,980 & 0 & 1,980 & 111,000 & 24,300 & 87,000 & 26,300 & 0 & 0 & 87,000 & 33,500 & 53,100 & 59,800 \\
\hline Other than $\mathrm{Al}$ Components, $\mathrm{kg}$ & 11,800 & 251 & 12,000 & 205,000 & 44,900 & 160,000 & 56,900 & 0 & 0 & 160,000 & 61,800 & 98,000 & 119,000 \\
\hline Max Settling Time (days) & - & & & & - & & & - & - & & - & & \\
\hline
\end{tabular}

Note: Yellow blocks indicate initial conditions/inputs to the material balance calculation. Blue headers highlight columns specific to Tank 51. 
SRNL-STI-2008-00389

REVISION 0

Table 12: Material Balance (continued)

(assuming $80 \%$ of the aluminum dissolves)

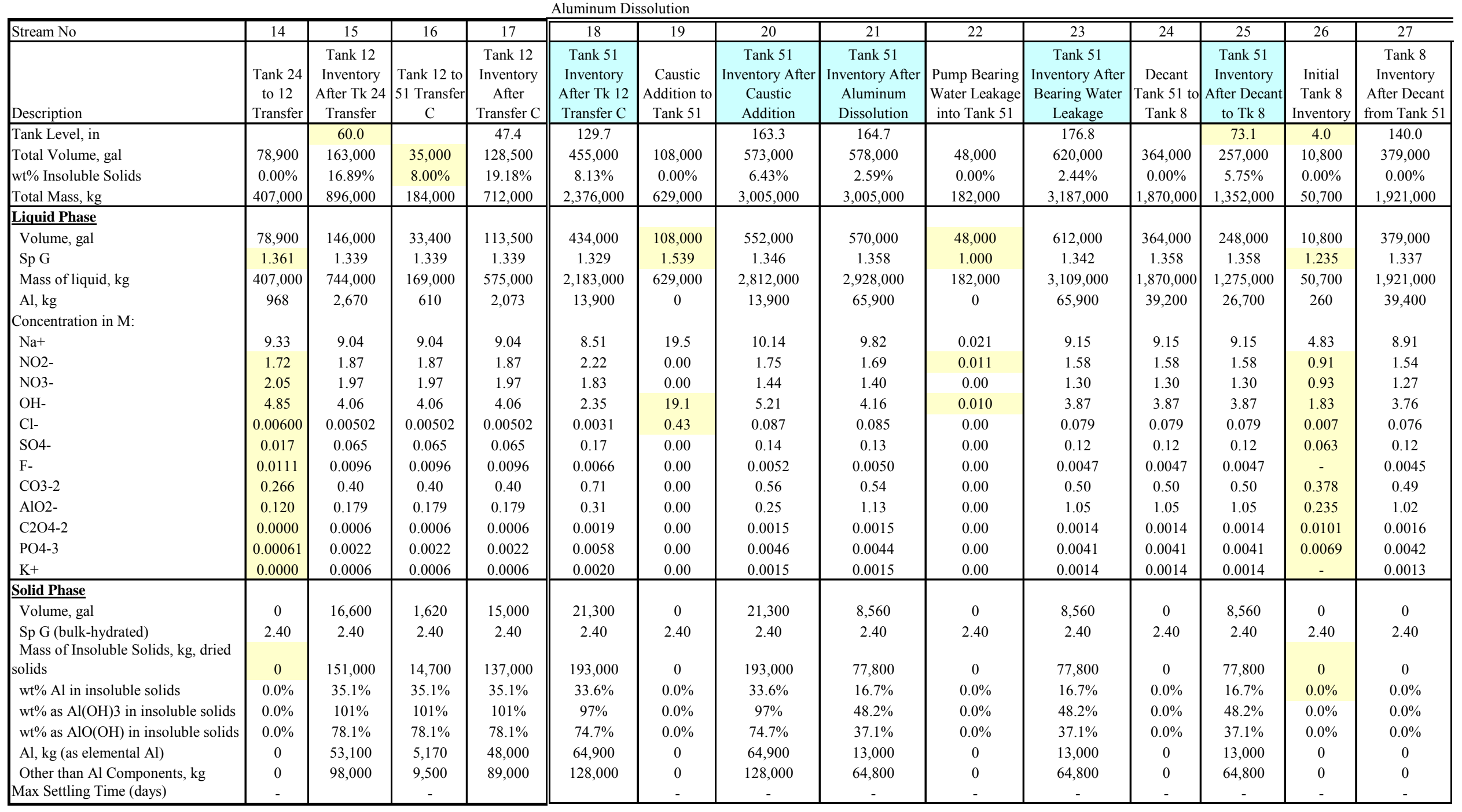


SRNL-STI-2008-00389

REVISION 0

Table 12: Material Balance (continued)

(assuming $80 \%$ of the aluminum dissolves)

\begin{tabular}{|c|c|c|c|c|c|c|c|c|c|c|c|c|c|c|}
\hline \multirow[b]{2}{*}{ Stream No } & \multicolumn{2}{|l|}{$\mathrm{Pu}$ Addition } & \multicolumn{5}{|l|}{ Wash 1} & \multicolumn{7}{|c|}{ Tank 4 Sludge Slurry Transfer to Tank 51} \\
\hline & \begin{tabular}{|l|}
28 \\
\end{tabular} & 29 & \begin{tabular}{|l|}
30 \\
\end{tabular} & 31 & 32 & 33 & 34 & 35 & \begin{tabular}{|l|}
36 \\
\end{tabular} & \begin{tabular}{|l|}
37 \\
\end{tabular} & 38 & 39 & 40 & 41 \\
\hline Description & $\begin{array}{c}\text { Second } \mathrm{Pu} \\
\text { Transfers } \\
\text { from } 221-\mathrm{H} \\
\text { to Tank } 51 \\
\end{array}$ & $\begin{array}{c}\text { Tank } 51 \\
\text { Inventory } \\
\text { After Pu } \\
\text { Addition } \\
\end{array}$ & $\begin{array}{c}\text { Inhibited } \\
\text { Water } \\
\text { Addition } \\
\end{array}$ & $\begin{array}{c}\text { Tank } 51 \\
\text { Inventory } \\
\text { After IW } \\
\text { Addition } \\
\end{array}$ & \begin{tabular}{|c|} 
Decant A \\
Tank 51 to \\
Tank 8 \\
\end{tabular} & \begin{tabular}{|c|} 
Tank 8 \\
Inventory \\
After Decant \\
from Tank 51 \\
\end{tabular} & \begin{tabular}{|c|} 
Tank 51 \\
Inventory After \\
Decant to Tank \\
8 \\
\end{tabular} & \begin{tabular}{||c} 
Tank 4 Sludge \\
Slurry Transfer \\
to Tank 51 \\
\end{tabular} & \begin{tabular}{|c|} 
Dilution and \\
Flush Water \\
in Trans. from \\
Tank 4 \\
\end{tabular} & \begin{tabular}{|c|} 
Tank 51 \\
Inventory \\
After Tank 4 \\
Transfer \\
\end{tabular} & \begin{tabular}{|c|} 
Decant B \\
Tank 51 to \\
3 H Evap \\
System \\
\end{tabular} & \begin{tabular}{|c|} 
Tank 51 \\
Inventory After \\
Decant to $3 \mathrm{H}$ \\
Evap System \\
\end{tabular} & \begin{tabular}{|c|} 
Decant C \\
Tank 51 to \\
2 F Evap \\
System \\
\end{tabular} & \begin{tabular}{|c|} 
Tank 51 \\
Inventory After \\
Decant to $2 \mathrm{~F}$ \\
Evap System \\
\end{tabular} \\
\hline Tank Level, in & & 80.9 & & 135.9 & & & 93.2 & & & 223.2 & & 189.0 & & 103.5 \\
\hline Total Volume, gal & 24,100 & 284,000 & 193,000 & 477,000 & 150,000 & 525,000 & 327,000 & 396,000 & 60,000 & 783,000 & 120,000 & 663,000 & 300,000 & 363,000 \\
\hline $\mathrm{wt} \%$ Insoluble Solids & $2.33 \%$ & $5.48 \%$ & $0.00 \%$ & $3.61 \%$ & $0.00 \%$ & $0.00 \%$ & $5.23 \%$ & $2.70 \%$ & $0.00 \%$ & $3.59 \%$ & $0.00 \%$ & $4.23 \%$ & $0.00 \%$ & $7.59 \%$ \\
\hline Total Mass, kg & 119,000 & $1,471,000$ & 758,000 & $2,229,000$ & 688,000 & $2,609,000$ & $1,541,000$ & $1,875,000$ & 234,000 & $3,650,000$ & 549,000 & $3,101,000$ & $1,374,000$ & $1,728,000$ \\
\hline \multicolumn{15}{|l|}{ Liquid Phase } \\
\hline Volume, gal & 23,800 & 275,000 & 193,000 & 468,000 & 150,000 & 525,000 & 318,000 & 391,000 & 60,000 & 769,000 & 120,000 & 649,000 & 300,000 & 349,000 \\
\hline $\mathrm{Sp} \mathrm{G}$ & 1.286 & 1.335 & 1.037 & 1.212 & 1.212 & 1.314 & 1.212 & 1.234 & 1.030 & 1.209 & 1.209 & 1.209 & 1.209 & 1.209 \\
\hline Mass of liquid, $\mathrm{kg}$ & 116,000 & $1,390,000$ & 758,000 & $2,149,000$ & 688,000 & $2,609,000$ & $1,460,000$ & $1,825,000$ & 234,000 & $3,519,000$ & 549,000 & $2,970,000$ & $1,374,000$ & $1,597,000$ \\
\hline $\mathrm{Al}, \mathrm{kg}$ & 67 & 26,800 & 0 & 26,800 & 8,600 & 48,000 & 18,200 & 4,220 & 0 & 22,400 & 3,500 & 18,900 & 8,750 & 10,170 \\
\hline \multicolumn{15}{|l|}{ Concentration in M: } \\
\hline $\mathrm{Na}+$ & 5.457 & 8.72 & 1.211 & 5.62 & 5.62 & 8.05 & 5.62 & 4.85 & 1.00 & 4.87 & 4.87 & 4.87 & 4.87 & 4.87 \\
\hline NO2- & 0.013 & 1.42 & 0.011 & 0.84 & 0.84 & 1.35 & 0.84 & 1.21 & 0.00 & 0.96 & 0.96 & 0.96 & 0.96 & 0.96 \\
\hline NO3- & 4.100 & 1.53 & 0.00 & 0.90 & 0.90 & 1.18 & 0.90 & 1.35 & 0.00 & 1.06 & 1.06 & 1.06 & 1.06 & 1.06 \\
\hline SO4- & 0.00060 & 0.11 & 0.00 & 0.065 & 0.065 & 0.105 & 0.065 & 0.16 & 0.00 & 0.110 & 0.110 & 0.110 & 0.110 & 0.110 \\
\hline F- & 0.0631 & 0.0097 & 0.00 & 0.0057 & 0.0057 & 0.0049 & 0.0057 & 0.0035 & 0.00 & 0.0041 & 0.0041 & 0.0041 & 0.0041 & 0.0041 \\
\hline $\mathrm{CO} 3-2$ & 0.000 & 0.45 & 0.00 & 0.27 & 0.27 & 0.43 & 0.27 & 0.39 & 0.00 & 0.31 & 0.31 & 0.31 & 0.31 & 0.31 \\
\hline $\mathrm{AlO} 2-$ & 0.027 & 0.95 & 0.00 & 0.56 & 0.56 & 0.90 & 0.56 & 0.11 & 0.00 & 0.29 & 0.29 & 0.29 & 0.29 & 0.29 \\
\hline $\mathrm{C} 2 \mathrm{O} 4-2$ & 0.0067 & 0.0018 & 0.00 & 0.0011 & 0.0011 & 0.0015 & 0.0011 & 0.0039 & 0.00 & 0.0024 & 0.0024 & 0.0024 & 0.0024 & 0.0024 \\
\hline PO4-3 & 0.0076 & 0.0044 & 0.00 & 0.0026 & 0.0026 & 0.0037 & 0.0026 & 0.0032 & 0.00 & 0.0027 & 0.0027 & 0.0027 & 0.0027 & 0.0027 \\
\hline $\mathrm{K}+$ & 0.031 & 0.0039 & 0.00 & 0.0023 & 0.0023 & 0.0016 & 0.0023 & 0.036 & 0.00 & 0.019 & 0.019 & 0.019 & 0.019 & 0.019 \\
\hline \multicolumn{15}{|l|}{ Solid Phase } \\
\hline Volume, gal & 304 & 8,870 & 0 & 8,870 & 0 & 0 & 8,870 & 5,560 & 0 & 14,400 & 0 & 14,400 & 0 & 14,400 \\
\hline $\begin{array}{l}\text { Sp G (bulk-hydrated) } \\
\text { Mass of Insoluble Solids, kg, dried }\end{array}$ & 2.40 & 2.40 & 2.40 & 2.40 & 2.40 & 2.40 & 2.40 & 2.40 & 2.40 & 2.40 & 2.40 & 2.40 & 2.40 & 2.40 \\
\hline solids & 2,762 & 80,600 & 0 & 80,600 & 0 & 0 & 80,600 & 50,500 & 0 & 131,000 & 0 & 131,000 & 0 & 131,000 \\
\hline $\mathrm{wt} \% \mathrm{Al}$ in insoluble solids & $0.0 \%$ & $16.1 \%$ & $0.0 \%$ & $16.1 \%$ & $0.0 \%$ & $0.0 \%$ & $16.1 \%$ & $7.0 \%$ & $0.0 \%$ & $12.6 \%$ & $0.0 \%$ & $12.6 \%$ & $0.0 \%$ & $12.6 \%$ \\
\hline $\mathrm{wt} \%$ as $\mathrm{Al}(\mathrm{OH}) 3$ in insoluble solids & $0.0 \%$ & $46.6 \%$ & $0.0 \%$ & $46.6 \%$ & $0.0 \%$ & $0.0 \%$ & $46.6 \%$ & $20.3 \%$ & $0.0 \%$ & $36.4 \%$ & $0.0 \%$ & $36.4 \%$ & $0.0 \%$ & $36.4 \%$ \\
\hline $\mathrm{wt} \%$ as $\mathrm{AlO}(\mathrm{OH})$ in insoluble solids & $0.0 \%$ & $35.8 \%$ & $0.0 \%$ & $35.8 \%$ & $0.0 \%$ & $0.0 \%$ & $35.8 \%$ & $15.6 \%$ & $0.0 \%$ & $28.0 \%$ & $0.0 \%$ & $28.0 \%$ & $0.0 \%$ & $28.0 \%$ \\
\hline $\mathrm{Al}, \mathrm{kg}$ (as elemental $\mathrm{Al})$ & 0 & 13,000 & 0 & 13,000 & 0 & 0 & 12,990 & 3,550 & 0 & 16,500 & 0 & 16,500 & 0 & 16,500 \\
\hline Other than $\mathrm{Al}$ Components, $\mathrm{kg}$ & 2,760 & 67,600 & 0 & 67,600 & 0 & 0 & 67,576 & 47,000 & 0 & 114,600 & 0 & 114,600 & 0 & 114,600 \\
\hline Max Settling Time (days) & & - & - & - & - & - & - & - & - & - & - & - & - & - \\
\hline
\end{tabular}


SRNL-STI-2008-00389

REVISION 0

Table 12: Material Balance (continued)

(assuming $80 \%$ of the aluminum dissolves)

\begin{tabular}{|c|c|c|c|c|c|c|c|c|c|c|c|c|c|c|c|c|}
\hline \multirow[b]{2}{*}{ Stream No } & \multicolumn{4}{|l|}{ Wash 2} & \multicolumn{4}{|l|}{ Wash 3} & \multicolumn{4}{|l|}{ Wash 4} & \multicolumn{4}{|l|}{ Wash 5} \\
\hline & 42 & 43 & 44 & 45 & \begin{tabular}{||l|}
46 \\
\end{tabular} & 47 & 48 & 49 & 50 & 51 & 52 & 53 & 54 & 55 & 56 & 57 \\
\hline Description & $\begin{array}{l}\text { Inhibited } \\
\text { Water } \\
\text { Addition }\end{array}$ & $\begin{array}{c}\text { Tank } 51 \\
\text { Inventory } \\
\text { After IW } \\
\text { Addition }\end{array}$ & \begin{tabular}{|c|} 
Decant D \\
Tank 51 to \\
2F Evap \\
System
\end{tabular} & \begin{tabular}{|c||} 
Tank 51 \\
Inventory After \\
Decant to $2 \mathrm{~F}$ \\
Evap System \\
\end{tabular} & \begin{tabular}{|l} 
Inhibited \\
Water \\
Addition
\end{tabular} & $\begin{array}{c}\text { Tank } 51 \\
\text { Inventory } \\
\text { After IW } \\
\text { Addition }\end{array}$ & \begin{tabular}{|c|} 
Decant E \\
Tank 51 to \\
2F Evap \\
System \\
\end{tabular} & \begin{tabular}{|c||} 
Tank 51 \\
Inventory After \\
Decant to $2 \mathrm{~F}$ \\
Evap System
\end{tabular} & \begin{tabular}{|l} 
Inhibited \\
Water \\
Addition
\end{tabular} & $\begin{array}{c}\text { Tank } 51 \\
\text { Inventory } \\
\text { After IW } \\
\text { Addition }\end{array}$ & $\begin{array}{c}\text { Decant } \mathrm{F} \\
\text { Tank } 51 \text { to } \\
2 \mathrm{~F} \text { Evap } \\
\text { System } \\
\end{array}$ & \begin{tabular}{c|} 
Tank 51 \\
Inventory After \\
Decant to $2 \mathrm{~F}$ \\
Evap System \\
\end{tabular} & $\begin{array}{l}\text { Inhibited } \\
\text { Water } \\
\text { Addition }\end{array}$ & $\begin{array}{c}\text { Tank } 51 \\
\text { Inventory } \\
\text { After IW } \\
\text { Addition } \\
\end{array}$ & $\begin{array}{c}\text { Decant G } \\
\text { Tank } 51 \text { to } \\
\text { 2F Evap } \\
\text { System }\end{array}$ & \begin{tabular}{|c|} 
Tank 51 \\
Inventory After \\
Decant to $2 \mathrm{~F}$ \\
Evap System \\
\end{tabular} \\
\hline Tank Level, in & & 163.3 & & \begin{tabular}{|l|}
101.3 \\
\end{tabular} & & 166.4 & & \begin{tabular}{|l||}
98.4 \\
\end{tabular} & & 165.4 & & 98.4 & & 126.0 & & 84.3 \\
\hline Total Volume, gal & 210,000 & 573,000 & 218,000 & 356,000 & 228,000 & 584,000 & 238,000 & 345,000 & 235,000 & 580,000 & 235,000 & 345,000 & 97,000 & 442,000 & 146,000 & 296,000 \\
\hline wt $\%$ Insoluble Solids & $0.00 \%$ & $5.20 \%$ & $0.00 \%$ & $8.24 \%$ & $0.00 \%$ & $5.34 \%$ & $0.00 \%$ & $8.85 \%$ & $0.00 \%$ & $5.53 \%$ & $0.00 \%$ & $9.10 \%$ & $0.00 \%$ & $7.25 \%$ & $0.00 \%$ & $10.62 \%$ \\
\hline Total Mass, kg & 795,000 & $2,523,000$ & 932,000 & $1,591,000$ & 865,000 & $2,456,000$ & 973,000 & $1,482,000$ & 890,000 & $2,372,000$ & 931,000 & $1,441,000$ & 367,000 & $1,808,000$ & 574,000 & $1,234,000$ \\
\hline \multicolumn{17}{|l|}{ Liquid Phase } \\
\hline Volume, gal & 210,000 & 559,000 & 218,000 & 341,000 & 228,000 & 570,000 & 238,000 & 331,000 & 235,000 & 566,000 & 235,000 & 331,000 & 97,000 & 428,000 & 146,000 & 281,000 \\
\hline $\mathrm{Sp} \mathrm{G}$ & 1.000 & 1.130 & 1.130 & 1.130 & 1.000 & 1.078 & 1.078 & 1.078 & 1.000 & 1.046 & 1.046 & 1.046 & 1.000 & 1.035 & 1.035 & 1.035 \\
\hline Mass of liquid, kg & 795,000 & $2,392,000$ & 932,000 & $1,460,000$ & 865,000 & $2,324,000$ & 973,000 & $1,351,000$ & 890,000 & $2,241,000$ & 931,000 & $1,310,000$ & 367,000 & $|1,677,000|$ & 574,000 & $1,103,000$ \\
\hline $\mathrm{Al}, \mathrm{kg}$ & 0 & 10,170 & 3,960 & 6,210 & 0 & 6,210 & 2,600 & 3,610 & 0 & 3,610 & 1,500 & 2,110 & 0 & 2,110 & 720 & 1,390 \\
\hline \multicolumn{17}{|l|}{ Concentration in M: } \\
\hline $\mathrm{Na}^{+}$ & 0.021 & 3.05 & 3.05 & 3.05 & 0.972 & 2.21 & 2.21 & 2.21 & 0.021 & 1.30 & 1.30 & 1.30 & 0.021 & 1.01 & 1.01 & 1.01 \\
\hline NO2- & 0.011 & 0.60 & 0.60 & 0.60 & 0.962 & 0.75 & 0.75 & 0.75 & 0.011 & 0.44 & 0.44 & 0.44 & 0.011 & 0.34 & 0.34 & 0.34 \\
\hline NO3- & 0.00 & 0.66 & 0.66 & 0.66 & 0.00 & 0.40 & 0.40 & 0.40 & 0.00 & 0.23 & 0.23 & 0.23 & 0.00 & 0.18 & 0.18 & 0.18 \\
\hline OH- & 0.010 & 1.06 & 1.06 & 1.06 & 0.010 & 0.64 & 0.64 & 0.64 & 0.010 & 0.38 & 0.38 & 0.38 & 0.010 & 0.29 & 0.29 & 0.29 \\
\hline $\mathrm{Cl}-$ & 0.00 & 0.015 & 0.015 & 0.015 & 0.00 & 0.0088 & 0.0088 & 0.0088 & 0.00 & 0.0052 & 0.0052 & 0.0052 & 0.00 & 0.0040 & 0.0040 & 0.0040 \\
\hline F- & 0.00 & 0.0026 & 0.0026 & 0.0026 & 0.00 & 0.00154 & 0.00154 & 0.00154 & 0.00 & 0.00090 & 0.00090 & 0.00090 & 0.00 & 0.00069 & 0.00069 & 0.00069 \\
\hline $\mathrm{CO} 3-2$ & 0.00 & 0.19 & 0.19 & 0.19 & 0.00 & 0.11 & 0.11 & 0.11 & 0.00 & 0.07 & 0.07 & 0.07 & 0.00 & 0.05 & 0.05 & 0.05 \\
\hline AlO2- & 0.00 & 0.18 & 0.18 & 0.18 & 0.00 & 0.11 & 0.11 & 0.11 & 0.00 & 0.06 & 0.06 & 0.06 & 0.00 & 0.05 & 0.05 & 0.05 \\
\hline $\mathrm{C} 2 \mathrm{O} 4-2$ & 0.00 & 0.00153 & 0.00153 & 0.00153 & 0.00 & 0.00091 & 0.00091 & 0.00091 & 0.00 & 0.00053 & 0.00053 & 0.00053 & 0.00 & 0.00041 & 0.00041 & 0.00041 \\
\hline PO4-3 & 0.00 & 0.0017 & 0.0017 & 0.0017 & 0.00 & 0.00101 & 0.00101 & 0.00101 & 0.00 & 0.00059 & 0.00059 & 0.00059 & 0.00 & 0.00046 & 0.00046 & 0.00046 \\
\hline $\mathrm{K}+$ & 0.00 & 0.0119 & 0.0119 & 0.0119 & 0.00 & 0.0071 & 0.0071 & 0.0071 & 0.00 & 0.0042 & 0.0042 & 0.0042 & 0.00 & 0.0032 & 0.0032 & 0.0032 \\
\hline \multicolumn{17}{|l|}{ Solid Phase } \\
\hline Volume, gal & 0 & 14,400 & 0 & 14,400 & 0 & 14,400 & 0 & 14,400 & 0 & 14,400 & 0 & 14,400 & 0 & 14,400 & 0 & 14,400 \\
\hline $\begin{array}{l}\text { Sp G (bulk-hydrated) } \\
\text { Mass of Insoluble Solids, kg, dried }\end{array}$ & 2.40 & 2.40 & 2.40 & 2.40 & 2.40 & 2.40 & 2.40 & 2.40 & 2.40 & 2.40 & 2.40 & 2.40 & 2.40 & 2.40 & 2.40 & 2.40 \\
\hline solids & 0 & 131,000 & 0 & 131,000 & 0 & 131,000 & 0 & 131,000 & 0 & 131,000 & 0 & 131,000 & 0 & 131,000 & 0 & 131,000 \\
\hline $\mathrm{wt} \% \mathrm{Al}$ in insoluble solids & $0.0 \%$ & $12.6 \%$ & $0.0 \%$ & $12.6 \%$ & $0.0 \%$ & $12.6 \%$ & $0.0 \%$ & $12.6 \%$ & $0.0 \%$ & $12.6 \%$ & $0.0 \%$ & $12.6 \%$ & $0.0 \%$ & $12.6 \%$ & $0.0 \%$ & $12.6 \%$ \\
\hline $\mathrm{wt} \%$ as $\mathrm{Al}(\mathrm{OH}) 3$ in insoluble solids & $0.0 \%$ & $36.4 \%$ & $0.0 \%$ & $36.4 \%$ & $0.0 \%$ & $36.4 \%$ & $0.0 \%$ & $36.4 \%$ & $0.0 \%$ & $36.4 \%$ & $0.0 \%$ & $36.4 \%$ & $0.0 \%$ & $36.4 \%$ & $0.0 \%$ & $36.4 \%$ \\
\hline $\mathrm{wt} \%$ as $\mathrm{AlO}(\mathrm{OH})$ in insoluble solids & $0.0 \%$ & $28.0 \%$ & $0.0 \%$ & $28.0 \%$ & $0.0 \%$ & $28.0 \%$ & $0.0 \%$ & $28.0 \%$ & $0.0 \%$ & $28.0 \%$ & $0.0 \%$ & $28.0 \%$ & $0.0 \%$ & $28.0 \%$ & $0.0 \%$ & $28.0 \%$ \\
\hline $\mathrm{Al}, \mathrm{kg}$ (as elemental $\mathrm{Al})$ & 0 & 16,500 & 0 & 16,500 & 0 & 16,500 & 0 & 16,500 & 0 & 16,500 & 0 & 16,500 & 0 & 16,500 & 0 & 16,500 \\
\hline Other than $\mathrm{Al}$ Components, $\mathrm{kg}$ & 0 & 114,600 & 0 & 114,600 & 0 & 114,600 & 0 & 114,600 & 0 & 114,600 & 0 & 114,600 & 0 & 114,600 & 0 & 114,600 \\
\hline Max Settling Time (days) & - & - & - & - & - & - & - & - & - & - & - & - & - & - & - & - \\
\hline
\end{tabular}

Note: Stream 46 includes a sodium nitrite addition to the wash water. Streams 30 and 36 include a sodium hydroxide addition to the wash water. 


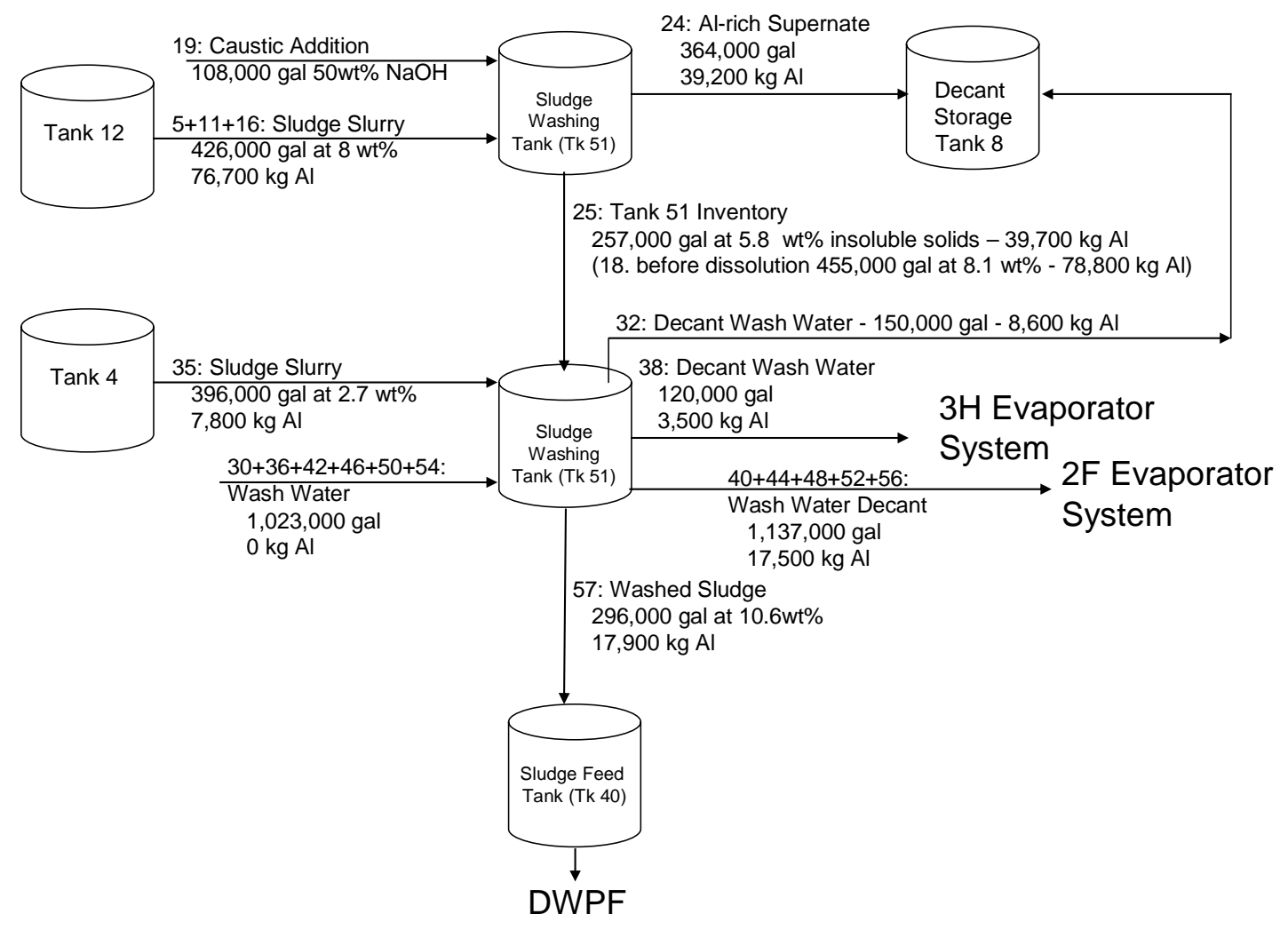

Figure 6: Aluminum Balance for Aluminum Dissolution in Tank 51

\subsection{Downstream Process Impacts}

\subsubsection{Impact on Saltstone Production Facility}

The aluminum-laden supernate decanted to Tank 8 is stored until fed to a salt waste treatment process such as the SWPF. The decontaminated salt solution will then be processed at the SPF. Table 13 shows the composition of the aluminum-laden supernate as estimated for storage in Tank 8 and after dilution to 5.6 $\mathrm{M}$ total sodium for comparison to the projected feed to the Saltstone Production Facility (SPF) from various salt processes and the estimated average composition of all soluble salt waste in the tank farms. The aluminum-laden supernate after dilution to $5.6 \mathrm{M}$ total sodium is:

- near average relative to free hydroxide concentrations,

- lower relative to average sodium nitrate concentrations,

- higher relative to average sodium nitrite, and sodium carbonate, and

- well above average aluminum concentrations.

Only the aluminum concentration is higher than most any other stream intended for salt waste processing. The high aluminum concentrations result from dissolving aluminum from a sludge slurry with 
exceptionally high aluminum content. It is likely that this stream can be blended with other waste supernates such that the aluminum concentration in the actual batch sent to salt waste processing is closer to average. ${ }^{3}$ High aluminum concentration in salt solution was identified in simulant testing to effect grout formation. Some of the effects were beneficial to processing and some were detrimental, so specific blend testing will likely be needed for salt waste processing. Since this risk exists in a large portion of the planned feed to the SWPF, the risk will need to be managed as part of the waste acceptance program for SWPF.

\section{Table 13: Ionic Concentration Data in Molarity for Al-Laden Supernate Stored in Tank 8 Compared to SWPF and SPF Estimated Feed Streams}

\begin{tabular}{|c|c|c|c|c|c|c|c|c|c|c|c|c|c|c|c|}
\hline \multicolumn{3}{|c|}{ Ion } & $\mathrm{Na}^{+}$ & $\mathrm{K}^{+}$ & $\mathrm{Cs}^{+}$ & $\mathrm{OH}^{-}$ & $\mathrm{NO}_{3}^{-}$ & $\mathrm{NO}_{2}^{-}$ & $\mathrm{Al}(\mathrm{OH})_{4}^{-}$ & $\mathrm{Al}$ (as metal) & $\mathrm{CO}_{3}{ }^{-2}$ & $\mathrm{SO}_{4}^{-2}$ & $\mathrm{Cl}^{-}$ & $\mathrm{F}^{-}$ & $\mathrm{PO}_{4}^{-3}$ \\
\hline \multicolumn{3}{|c|}{ Estimated Tank 8 Composition } & 8.1 & 0.0016 & - & 3.5 & 1.2 & 1.4 & 0.9 & - & 0.43 & 0.11 & 0.067 & 0.0049 & 0.0037 \\
\hline \multicolumn{3}{|c|}{ Estimated Tank 8 Composition (adjusted to $5.6 \mathrm{M}$} & 5.6 & 0.0011 & - & 2.4 & 0.82 & 0.94 & 0.63 & - & 0.30 & 0.073 & 0.047 & 0.0034 & 0.0026 \\
\hline \multicolumn{3}{|c|}{ Tank 11 Sample After LTAD ${ }^{\text {(Hay) }}$} & 4.17 & 0.0033 & - & 3.10 & 0.18 & 0.33 & 0.39 & - & 0.098 & 0.017 & 0.030 & $<0.026$ & $<0.013$ \\
\hline \multicolumn{3}{|c|}{ Bench-Scale Test Data $^{\text {(Reboul) }}$} & 5.1 & - & - & 3.80 & 0.22 & 0.42 & 0.36 & - & - & 0.021 & $<0.034$ & $<0.064$ & 0.001 \\
\hline \multirow{2}{*}{\multicolumn{2}{|c|}{$\begin{array}{l}\text { Initial Life Cycle Feed for } \\
\text { SWPF }^{\text {(Dimenna) }}\end{array}$}} & Min & 5.8 & 0.0059 & - & 1.21 & 0.57 & 0.065 & 0.061 & - & 0.011 & 0.014 & - & - & 0.002 \\
\hline & & Max & 6.9 & 0.051 & - & 5.03 & 3.41 & 1.21 & 0.47 & - & 1.98 & 1.61 & - & - & 0.016 \\
\hline \multirow{3}{*}{\multicolumn{2}{|c|}{ Standard Simulated Salt Waste ${ }^{\text {(Walker) }}$}} & Average & 5.6 & 0.015 & $1.40 \mathrm{E}-04$ & 1.91 & 2.14 & 0.52 & 0.31 & - & 0.16 & 0.15 & 0.025 & 0.032 & 0.01 \\
\hline & & High $\mathrm{OH}$ & 5.6 & 0.03 & $3.70 \mathrm{E}-04$ & 3.05 & 1.1 & 0.74 & 0.27 & - & 0.17 & 0.03 & 0.01 & 0.01 & 0.008 \\
\hline & & High NO3 & 5.6 & 0.0041 & $1.40 \mathrm{E}-04$ & 1.17 & 2.84 & 0.37 & 0.32 & - & 0.16 & 0.22 & 0.04 & 0.05 & 0.01 \\
\hline \multirow{2}{*}{\multicolumn{2}{|c|}{$\begin{array}{c}\text { Integrated Flowsheet Attainment } \\
\text { Study }^{\text {(Elder) }}\end{array}$}} & Min & 5.6 & 0.0050 & $2.69 \mathrm{E}-05$ & 0.42 & 1.41 & 0.12 & 0.032 & 0.023 & 0.097 & 0.029 & 0.00080 & 0.00018 & 0.0080 \\
\hline & & Max & 5.6 & 0.037 & $2.56 \mathrm{E}-04$ & 3.37 & 4.25 & 0.54 & 0.36 & 0.11 & 0.24 & 0.085 & 0.0059 & 0.0030 & 0.017 \\
\hline \multirow{2}{*}{\multicolumn{2}{|c|}{$\begin{array}{c}\text { DDA and ARP/MCU Feed } \\
\text { Basis }^{\text {(Drumm) }} \\
\end{array}$}} & DDA & 3.4 & - & - & 0.47 & 2.24 & 0.12 & 0.037 & - & 0.15 & 0.048 & 0.0012 & 0.0061 & - \\
\hline & & ARP/MCU & 5.7 & - & - & 1.21 & 3.44 & 0.33 & 0.022 & - & 0.19 & 0.065 & 0.0018 & 0.012 & - \\
\hline \multirow{6}{*}{$\begin{array}{l}\text { SPF Feed Stream } \\
\text { Data from } \\
\text { Spaceman Plus } \\
\text { from: } \text { (Pike 2007) }^{\text {. }}\end{array}$} & \multirow{2}{*}{ DDA } & Min & 2.76 & 0.0037 & $6.56 \mathrm{E}-10$ & 0.24 & 1.58 & 0.0049 & 0.013 & 0.024 & 0.074 & 0.013 & 0.0005 & 0.0001 & 0.004 \\
\hline & & Max & 3.56 & 0.016 & $1.27 \mathrm{E}-05$ & 0.70 & 2.49 & 0.22 & 0.12 & 0.059 & 0.19 & 0.056 & 0.0035 & 0.0087 & 0.010 \\
\hline & \multirow{2}{*}{$\mathrm{ARP} / \mathrm{MCU}$} & Min & 4.96 & 0.0005 & $1.21 \mathrm{E}-06$ & 0.13 & 1.25 & 0.076 & 0.0025 & 0.012 & 0.10 & 0.015 & 0.0006 & 0.0022 & 0.0057 \\
\hline & & Max & 6.67 & 0.023 & $5.94 \mathrm{E}-05$ & 2.85 & 5.42 & 0.79 & 0.13 & 0.145 & 0.28 & 0.109 & 0.0029 & 0.0196 & 0.019 \\
\hline & \multirow{2}{*}{ SWPF } & Min & 5.25 & 0.011 & $1.29 \mathrm{E}-04$ & 1.43 & 1.55 & 0.29 & 0.057 & 0.008 & 0.088 & 0.040 & 0.0023 & 0.0006 & 0.0049 \\
\hline & & Max & 5.26 & 0.029 & $2.27 \mathrm{E}-04$ & 2.83 & 2.97 & 0.58 & 0.15 & 0.069 & 0.16 & 0.065 & 0.0045 & 0.0024 & 0.012 \\
\hline \multirow{2}{*}{\multicolumn{2}{|c|}{$\begin{array}{l}\text { Tank 25 Salt Dissolution Flowsheet } \\
\text { Adjusted to 5.6 M Total } \mathrm{Na}^{\text {(Pike 2005) }}\end{array}$}} & High $\mathrm{Na}$ & 5.6 & - & - & 1.65 & 2.11 & 0.33 & 0.36 & - & 0.45 & 0.088 & 0.0044 & 0.032 & 0.0084 \\
\hline & & Low $\mathrm{Na}$ & 5.6 & - & - & 0.39 & 4.42 & 0.081 & 0.087 & - & 0.13 & 0.13 & 0.0011 & 0.016 & 0.029 \\
\hline
\end{tabular}

Note that the references on the table are as follows: Reboul is reference 37, Dimenna is reference 38, Hay is reference 39, Walker is reference 40, Elder is reference 41, Drumm is reference 42, Pike 2007 is reference 43, and Pike 2005 is reference 44.

\subsubsection{Impact on F-Tank Farm}

\subsubsection{Tank 8}

By design, the aluminum concentration in the initial decant liquid is projected at roughly the solubility of aluminum in Tank 8 at $20^{\circ} \mathrm{C}$ per calculation by OLI Steam Analyzer ${ }^{\mathrm{tm}}$ as shown in Figure 4 . The current plan includes transferring the first wash decant to Tank 8. If the dissolution process achieves the maximum extent of dissolution expected, $80 \%$, then $\mathrm{NaOH}$ would need to be added directly to Tank 8 to avoid precipitation of aluminum during storage. The size of the caustic addition depends on the margin necessary for storage.

Aluminum solubility decreases with decreasing hydroxide concentration. One known mechanism for hydroxide depletion is by absorption of carbon dioxide from the tank vapor space. The depletion rate depends on the ventilation rate of the waste tank. Assuming a ventilation rate of $300 \mathrm{scfm}$, the maximum hydroxide depletion rate is $0.02 \mathrm{M} /$ year for the projected 525,000 gallon transfer to Tank 8 based on an average atmospheric carbon dioxide concentration of $316 \mathrm{ppm}^{45}$ The depletion rate is very slow and will 
need to be monitored for the duration of storage to avoid precipitating solids. After 6 years of storage, the hydroxide concentration could drop from 3.47 to $3.34 \mathrm{M}$ where the aluminum solubility drops to $0.69 \mathrm{M}$ at $20^{\circ} \mathrm{C}$. The minimum hydroxide concentration that needs to be maintained depends on the success of the dissolution process. If $80 \%$ of the aluminum dissolves, the hydroxide concentration should be maintained at or above $4.0 \mathrm{M}$. This value will be evaluated based on the actual results. The corrosion chemistry program already provides adequate sampling for monitoring purposes. Aluminate ion analysis will need to be added to the analytical request for these samples as was done for the aluminum-laden supernate stored in Tank 11 from SB5.

Note that the first wash decant solution is currently shown to be transferred to Tank 8 and is included in the evaluation above. As noted earlier, the mixture in Tank 8 as shown in the material balance in Section 4.7 is at or above saturation at less than $28^{\circ} \mathrm{C}$, thus, the solution is already above saturation at $3.47 \mathrm{M}$ hydroxide. To prevent precipitation down to $20^{\circ} \mathrm{C}$, about 18,000 gallons of $50 \mathrm{wt} \%$ caustic would be needed to increase the hydroxide concentration to $4.0 \mathrm{M}$. Therefore, additional caustic would be needed to maintain some marginal allowance for depletion due to carbon dioxide absorption. The first wash decant would be transferred to the $3 \mathrm{H}$ evaporator system if not sent to Tank 8 , thus, eliminating the precipitation issue with the mixed solutions.

\section{CONCLUSIONS}

About $80 \%$ of the insoluble solids in Tank 12 sludge slurry are aluminum compounds, most likely boehmite. An aluminum dissolution process can dissolve up to $80 \%$ of the aluminum, dramatically reducing the total amount of insoluble solids in the slurry.

As planned, an aluminum removal process can reduce the aluminum in SB6 from about $84,500 \mathrm{~kg}$ to as little as $17,900 \mathrm{~kg}$ with a corresponding reduction of total insoluble solids in the batch from $246,000 \mathrm{~kg}$ to $131,000 \mathrm{~kg}$. The extent of the reduction may be limited by the time available to maintain Tank 51 at dissolution temperature. The range of dissolution in four weeks based on the known variability in dissolution kinetics can range from 44 to more than $80 \%$. At $44 \%$ of the aluminum dissolved, the mass reduction is approximately $1 / 2$ of the mass noted above, i.e., $33,300 \mathrm{~kg}$ of aluminum instead of $66,600 \mathrm{~kg}$. Planning to reach $80 \%$ of the aluminum dissolved should allow a maximum of 81 days for dissolution and reduce the allowance if test data shows faster kinetics. $47,800 \mathrm{~kg}$ of the dissolved aluminum will be stored in Tank 8 and $21,000 \mathrm{~kg}$ will be stored in saltcake via evaporation. Up to $77 \%$ of the total aluminum planned for SB6 may be removed via aluminum dissolution.

Storage of the aluminum-laden supernate in Tank 8 will require routine evaluation of the free hydroxide concentration in order to maintain aluminum in solution. Periodic evaluation will be established on concurrent frequency with corrosion program samples as previously established for aluminum-laden supernate from SB5 that is stored in Tank 11. 


\section{REFERENCES}

1 J. A. Pike, "Technical Evaluation for the Resumption of Aluminum Dissolution", CBU-LTS-200600100, Rev. 0, April 12, 2006, p. 5.

2 B. A. Hamm and H. H. Elder, "Savannah River Site Sludge Characterization Model Using Dial-Up Factors", CBU-PIT-2006-00058, Rev. 0, March 2006, p. 8.

3 J. A. Pike, "Evaluation of Low Temperature Aluminum Dissolution in Tank 51", SRNS-STI-200800021, Rev. 0, September 2008.

4 J. A. Pike, "Preliminary Results for Low Temperature Aluminum Removal from SB5", LWO-LWE2008-00067, Rev. 0, March 24, 2008.

5 A. L. Pajunen, "Evaluation of Boehmite Dissolution Kinetics in Tank Waste" LWO-PIT-2006-00006, Rev. 0, September 28, 2006.

6 B. B. Spencer, J. L. Collins, and R. D. Hunt, "Caustic Leaching of SRS Tank 12H Sludge With and Without Chelating Agents", ORNL/TM-2002/195, April 2003, p. 29.

7 J. A. Pike, "Preliminary Process Parameters for Aluminum Dissolution", CBU-PIT-2006-00082, Rev. 0, May 8, 2006.

8 “Works Technical Department Report for June 1973”, DPSP-73-1-6, June 1973, p. 62.

9 J. A. Pike, "ITP Precipitate Washing: Sample Variability in Tank Chemistry Samples", WER-WME920665, May 13, 1992.

10 Serial reference to monthly reports from March 1955 through 1995.

11 Tank Farm Sample Database, Wg08\SAMPLES \HLW Tank Chemistry\NTank12, September 1, 2008.

12 “Waste Management Incident Report WMI-84-5-4”, DPSP 84-17-5, May 9, 1984.

13 B. A. Weirsma, "Estimation of the Composition of the Waste in Tank 12 During the Initial Stages of Bulk Waste Removal", X-CLC-H-00584, Rev. 1, September 26, 2007, p. 3.

14 Waste Characterization System 1.5 maintained by the Liquid Waste Organization as of June 19, 2008

15 J. A. Pike, “Tank 11 Estimated Evaporation Rates”, WER-HLE-930233, September 28, 1993.

16 D. T. Hobbs, “Absoption of Carbon Dioxide in Waste Tanks”, DPST-87-596, September 3, 1987, p. 4.

17 R. S. Ondrejcin, "Nitrite Ingrowth and Stress Corrosion Characterization of Tank 11H Supernate", DPST-75-507, November 25, 1975.

18 S. H. Reboul and K. E. Zeigler, "Elemental Composition of Tank 12 Sludge Slurry Solids", SRNLL3100-2008-00010, September 12, 2008, p. 1. 
19 S. H. Reboul, "Density and Solids Measurements of Tank 12 Sludge Sample \#HTF-12-08-112", SRNL-L3100-2008-00089, October 28, 2008.

20 S. H. Reboul, “Tank 12 Sludge Constituents for Aluminum Dissolution Flowsheet”, SRNL-L31002008-00050, October 8, 2008, p. 2.

21 C. J. Bannochie, H. M. Ajo, D. R. Click, and J. M. Pareizs, “Tank 51 SB5 Qualification Sample Elemental Slurry Composition”, SRNL-PSE-2008- 00087, Rev. 0, April 21, 2008.

22 C. J. Bannochie, “Tank 51 SB5 Qualification Sample Elemental Supernate Composition”, SRNLPSE-2008-00097, Rev. 0, April 30, 2008.

23 Tank Farm Sample Database, Wg08\SAMPLES $\backslash H L W$ Tank Chemistry\NTank8, September 10, 2008.

24 M. S. Hay, "Characterization of Core Samples from a Hardened Crust Layer in Tank 4F", WSRCTR-2005-00441, Rev. 0, September 28, 2005.

25 V. A. Chander, “Tank 4 Burkeite Dissolution and Removal Strategy”, LWO-LWE-2007-00063, Rev. 4, August 14, 2007.

26 H. Q. Colleran, “Characterization Report for Plutonium Waste Stream HCAN-SW-19”, SRNSN0000-2008-0111, October 31, 2008.

27 R. A. L. Eubanks, "H Canyon Special Waste Compliance Plan for Transfer of Legacy Plutonium Sweepings FMR and GFSI Material to 241-H Tank Farm (U)", X-WCP-H-00012, Rev. 2, January 24, 2008.

28 A. L. Pajunen, "Preliminary Aluminum Dissolution Parameters", LWO-PIT-2006-00057, Rev. 0, November 13, 2006.

29 M. S. Hay, K. Adu-Wusu, and D. J. McCabe, "Determination of the Fraction of Gibbsite and Boehmite Forms of Aluminum in the Tank 51H Sludge", WSRC-STI-2008-00366, Rev. 0, August 2008.

30 C. Cole“CSTF Corrosion Control Program”, WSRC-TR-2002-00327, Rev. 4, December 17, 2007.

31 B. Landeene, “CSTF Flammability Control Program”, WSRC-TR-2003-00087, Rev. 13, February 4, 2008 .

32 J. M. Gillam, "Projected Sludge Settling Results for SB5”, X-ESR-H-00130, March 26, 2008.

33 E. D. Lee, "Insoluble Solids Settling in Tank 51 during Baseline Runs", WSRC-RP-96-87, May 20, 1996.

34 J. R. Vitali, "Evaluation of Inhalation Dose Potential when Separation Distance between the Jet/Pump and Sludge is Less Than 24 Inches", X-CLC-G-00090, August 28, 2008.

35 L. D. Koffman, "User Guide for the ACM Evaporator Model User Interface", WSRC-RP-200200324, Rev. 0, June 17, 2002. 
36 T. Hang, "A Description of Phase-1 High Level Waste Evaporator Flowsheet Models", WSRC-TR2002-00268, Rev. 0, June 6, 2002.

37 S. H Reboul, et al., "Analytical Data for Post-Aluminum Dissolution Decant Solution”, SRNL-PSE2007-00261, Rev. 0, November 27, 2007.

38 R. A. Dimenna, et. al., "Bases, Assumptions, and Results of the Flowsheet Calculations for the Decision Phase Salt Disposition Alternatives”, WSRC-RP-99-00006, Rev. 3, May 2001, Appendix H.

39 M. S. Hay and D. J. McCabe, "Characterization of Tank 11H and Tank 51H Post Aluminum Dissolution Process Samples” WSRC-STI-2008-00227, Rev. 0, May 2008.

40 D. D. Walker, "Preparation of Simulated Waste Solutions", WSRC-TR-99-00116, Rev. 0, April 15, 1999.

41 H. H. Elder, et al., "Integrated Material Balance Flowsheet \& Attainment Study Final Report", CBUPED-2004-00046, Rev. 0, October 18, 2004.

42 M. D. Drumm, et al., "Chemical Concentrations in Salt Solution Feed to the Saltstone Production Facility from DDA and ARP/MCU Batches”, CBU-PIT-2005-00095, Rev. 0, April 19, 2005.

43 J. A. Pike and J. M. Gillam, "Flowsheet for Aluminum Removal from SB5", LWO-PIT-2007-00042, Rev. 2, September 26, 2007.

44 J. A. Pike, "Flowsheet and Physical Property Estimation for SRS Tank 25 Salt Dissolution", CBUPIT-2005-00081, Rev. 1, February 11, 2008.

45 D. T. Hobbs, “Absoption of Carbon Dioxide in Waste Tanks”, DPST-87-596, September 3, 1987, p. 4. 